\title{
Thermal Effects Associated with RF Exposures in Diagnostic MRI: Overview of Existing and Emerging Concepts of Protection
}

\author{
Johan S. van den Brink (D) \\ Philips Medical Systems, Best, Netherlands \\ Correspondence should be addressed to Johan S.van den Brink; johan.van.den.brink@philips.com
}

Received 29 March 2019; Accepted 15 May 2019; Published 17 June 2019

Academic Editor: Xiaodong Yang

Copyright (C) 2019 Johan S. van den Brink. This is an open access article distributed under the Creative Commons Attribution License, which permits unrestricted use, distribution, and reproduction in any medium, provided the original work is properly cited.

Apart from magnetic attraction risks, the primary biophysical concern associated with MRI is radiofrequency heating of the human body and associated discomfort, health deterioration, or potential burns. This paper reviews experimental data and numerical modeling of systemic (core and brain) temperature and local thermal effects associated with diagnostic MRI exposures at 1.5T $(64 \mathrm{MHz})$ and 3.0T $(128 \mathrm{MHz})$. Allowable temperatures and duration of systemic exposure are established based on knowledge of (short-term) human thermobiology. Longer term effects related to DNA damage or altered cellular pathways are not covered in this review. Updated limits are proposed for core temperature increase $\left(\leq 1.3^{\circ} \mathrm{C}\right)$ and for Specific Absorption $(<4 \mathrm{~kJ} / \mathrm{kg})$. The potential use of thermal dose (CEM43) for local thermal protection is described, and previously proposed exposure limit values are evaluated against available data from current MRI practice. Gaps in knowledge are identified, and recommendations for additional research are provided.

\section{Introduction}

Magnetic Resonance Imaging is a well-established diagnostic modality in Radiology, with an estimated installed base of over 30,000 units at $1.5 \mathrm{~T}$ and 3.0T, and more than 150 million patient examinations annually. The highest direct risk related to MRI is attraction of ferromagnetic objects, with potential lethal consequences. Biophysical, immediate effects of MRI exposures are nausea and dizziness (vestibular unrest caused by interaction with the magnetic field), nerve and muscular stimulation by the switching gradients, and tissue heating by the radiofrequency pulses. No long-term effects attributed to electromagnetic field exposures in MRI have been reported.

RF exposure for MRI differs from most general public, occupational, and clinical scenarios: intense RF pulses are necessary with significant cumulative whole-body energy deposition. Basic Restrictions and Exposure Limits developed by the International Committee on Nonionizing Radiation Protection (ICNIRP [1]) are based on the opinion that no adverse health effects other than those induced by temperature increase can be substantiated from available scientific evidence.

Temperature effects from MRI exposures were established in the late 1980 s of the previous century using volunteer experiments and thermophysiological modeling. Corresponding limits to whole-body and head RF power deposition, expressed as Specific Absorption Rate (SAR in $\mathrm{W} / \mathrm{kg}$ ), were derived in the MRI product safety standard IEC 60601-2-33 [2] to ensure that core temperature would not increase more than $1^{\circ} \mathrm{C}$ and would stay below $40^{\circ} \mathrm{C}$. A simplified version of the applicable limits is shown in Figure 1.

Duration of exposure and total deposited energy (Specific Absorption in $\mathrm{J} / \mathrm{kg}$ ) in relation to thermoregulatory and heat loss capabilities are the determining parameters for core temperature increase. Reconfirmation of SAR limits seems warranted in view of scientific advances and insights from many studies of RF exposure associated with mobile communication technology.

Advances in multiphysics modeling pointed to the significance of local RF and thermal hotspots, intentionally 


\begin{tabular}{|l|c|c|c|c|}
\cline { 2 - 5 } \multicolumn{1}{c|}{} & \multicolumn{2}{c|}{ Global Exposure } & \multicolumn{2}{c|}{ Local Exposure } \\
\cline { 2 - 5 } \multicolumn{1}{c|}{} & & \multicolumn{3}{c|}{} \\
\cline { 2 - 5 } \multicolumn{1}{c|}{} & Whole Body SAR & Head SAR & Local Torso 10g SAR & Local Extremity 10g SAR \\
\hline Normal Mode & $2 \mathrm{~W} / \mathrm{kg}$ & $3.2 \mathrm{~W} / \mathrm{kg}$ & $10 \mathrm{~W} / \mathrm{kg}$ & $20 \mathrm{~W} / \mathrm{kg}$ \\
\hline First Level Controlled Mode & $4 \mathrm{~W} / \mathrm{kg}$ & $3.2 \mathrm{~W} / \mathrm{kg}$ & $20 \mathrm{~W} / \mathrm{Kg}$ & $40 \mathrm{~W} / \mathrm{kg}$ \\
\hline
\end{tabular}

FIGURE 1: Limits to RF exposure in MRI equipment [2]. For global exposure or protection from systemic thermal effects, 6-minuteaveraged whole body SAR and head SAR must be controlled. Additional limits apply to control local exposure, e.g., from small RF coils or inhomogeneous RF fields. This table contains only a subset of requirements; refer to [2] for detailed specifications including partial body SAR, short-term SAR, and specific absorption (limits not shown).

used for tumor treatment in RF hyperthermia. Effectiveness of cell killing correlates with thermal dose [3], expressed as temperature exposure of tissue at cumulative equivalent minutes at $43^{\circ} \mathrm{C}$ (CEM43). No thermal risk is assumed to result if the Basic Safety Restriction for thermal dose is set to the lowest CEM43 level at which no apoptotic effects have been reported. The diagnostic ultrasound community has evaluated the usefulness of CEM43 to provide user feedback on potential thermal risks $[4,5]$ and has established that 1 CEM43 is a conservative safety threshold for fetal, neonatal, and adult exposure $[6,7]$. Higher thresholds have been proposed for MRI [8], taking into account tissue type and patient's health state, with 2 CEM43 proposed as a conservative safety threshold for MRI under all conditions.

The aim of this paper is to provide a systematic review of experimental data and modeling studies for core temperature rise in routine diagnostic MRI, which mostly operate at $1.5 \mathrm{~T}$ $(64 \mathrm{MHz})$ and 3.0T (128 MHz). Consistency of estimated core temperatures and limits to whole-body and head SAR will be evaluated and considered in the context of predicting local temperature increases necessary to calculate CEM43. CEM43 is a potential Basic Safety Restriction metric for local thermal protection, and proposed exposure limit values for MRI are evaluated against available data from current MRI practice. This review weighs the evidence in support of advancing RF safety standards in MRI and identifies areas requiring further research.

\section{Methodology}

The literature review presented in this paper searches for RF effects associated with routine, whole-body MRI at $1.5 \mathrm{~T}$ and 3T. The search strategy includes an extended frequency range of 10-300 MHz. Thermal effects associated with therapeutic RF hyperthermia and systemic effects of occupational plane wave exposures in this frequency range are also included. The retrieved literature covers experiments and modeling of $\mathrm{RF}$ induced (instantaneous) physiological stress, defined as sweating, heat sensations, and potential tissue damage. Both systemic and local thermal effects are covered in the search, which include findings from RF hyperthermia. Excluded are effects on the genome and immune system (based on the epidemiologic assessment in [1]), long-term low-intensity effects, studies in the $\mathrm{GHz}$ frequency range, animal and cell model studies, and studies on the clinical effectiveness of hyperthermia. An evaluation of incidence and causes of RF burns is also not included in this paper.

Primary identification of relevant literature was performed using a broad, structured search on "health effects related to exposure to $\mathrm{RF}$ in the $\mathrm{MHz}$ regime" in Embase, using three search classes, radiofrequency, exposure type, and health effects, and narrowed down using three exclusion categories, frequency bands, device categories, and animal models and cancer. The search extended back to 1970, with first applicable papers found in 1986. A similar structured search was performed in Pubmed. The detailed search approach is provided in two tables in Appendix and was executed in September 2018 and repeated in March 2019 to confirm absence of additional recent publications. A total of 88 references were identified through Embase, and Pubmed resulted in 99 relevant hits after manual cleanup. Manual cleanup was necessary since esp. the Pubmed search provided many off-topic papers which were identified and excluded based on title and/or abstract. Combination of the two generated lists by removal of duplicates resulted in a total of 70 papers as baseline for this review.

All 70 papers were retrieved and read in detail to evaluate their relevance and to identify additional references pertinent to the purpose of this review. To this effect, three methods were used: (a) "snowballing", i.e., expanding the reference list by traces from the originally identified list, (b) "serendipitous discovery", adding narrow searches based on findings and ideas evolving during the review process), and (c) "personal knowledge", adding references from over 15 years of experience in the domain. This resulted in another 73 references, including those reporting and discussing thermophysiological risks in brain and eyes. In total 128 papers were evaluated in detail, with the following distribution: 46 review papers, 41 papers reporting original (measured) data, and 49 papers reporting electromagnetic and thermal simulations. Note that some papers fall in two or more categories.

In the following sections, (1) experimental temperature data for MRI RF exposures will be presented and discussed in relation to requirements for thermometry and RF dosimetry, (2) simulated predictions of core temperature under (sub$\mathrm{GHz}$ ) RF exposures will be summarized, (3) evidence for thermal thresholds for core, brain, and eyes will be related to expected temperatures in patients and in the fetus, and (4) the concept of CEM43 and its proposed use in MRI will be introduced and related to the history of safe use.

\section{Temperature Data from MRI Exposures: Systemic Burden}

MR equipment intentionally exposes patients to high $\mathrm{RF}$ power, generally for a short duration (less than 1 hour). RF deposition is expressed as Specific Absorption Rate (SAR 
in W/kg) and accumulated as Specific Absorption (SA in $\mathrm{J} / \mathrm{kg}$ ). The first generation MRI scanners operated at low SAR and initially exposed the head with local transmit coils. Increases in SAR levels to 2-4 W/kg were deemed necessary to ensure adequate image quality and scan efficiency for spine and body imaging, with total exposure durations of 20-40 minutes. In current practice, even longer examinations are not uncommon.

The acknowledged upper limit to whole-body SAR is 4 $\mathrm{W} / \mathrm{kg}$ [9], established from observed behavioral changes in animal studies. Such exposures are reported to induce strong heat sensations in healthy humans. A reduced whole-body SAR of $2 \mathrm{~W} / \mathrm{kg}$ already falls within normal variation due to metabolic activity and exercise: The average metabolic rate, as a conversion of chemical into mechanical and thermal energy in the human body, is estimated to be $115 \mathrm{~W}$ at rest and $295 \mathrm{~W}$ for moderate activity [10]. Thus, $2 \mathrm{~W} / \mathrm{kg}$ for a $100 \mathrm{~kg}$ person represents a situation of homeostasis without undue stress and is chosen as acceptable exposure for Normal Operating Mode of MRI systems, which all persons, regardless of health status, should be able to tolerate.

Several studies have evaluated the physiological implications of such exposures on healthy volunteers and patients, studying heart rate, blood pressure, sweating, and skin or core temperature. In the context of this review, core temperature is the only parameter of interest. Table 1 provides an overview of identified reports of temperature increase related to MRI exposures, including an example of a large whole-body study on RF hyperthermia. Note that most identified studies lack appropriate dosimetric information to confirm SAR and SA values. This may explain the anomaly of the reported mean temperature increase in [11], although also measurement approach and volunteer characteristics may explain a low core temperature increase. The high temperature increase in [12] indicates that patients may experience a higher core temperature increase than normal volunteers. In the hyperthermia setup, thermal insulation is applied, and thermoregulation may be compromised, while high-SAR levels are applied.

In previous assessments, reported mean core temperature increases were used to argue that effects are marginal. A more appropriate parameter to consider when establishing exposure limit values is the maximum reported core temperature increase, for which esophageal measurements are most accurate, but tympanic membrane temperatures can also provide representative data [20-25]. Total energy absorbed, or Specific Absorption (SA), provides an easy estimate for systemic thermal burden. Actual temperatures reached depend on many factors such as initial temperature distribution in the body, thermoregulatory capability, and dissipation options (clothing and blankets); see [25] and the section on core temperature predictions from simulation models. Irrespectively, the data suggests that an SA of approximately $4 \mathrm{~kJ} / \mathrm{kg}$ is sufficient to raise core temperature by $1^{\circ} \mathrm{C}$, which corresponds to a continuous high whole-body SAR ( $>3 \mathrm{~W} / \mathrm{kg}$ ) applied for 15-20 minutes. Predicted SA values in the tens of millions of MRI examinations performed annually can be assessed from scanner utilization data. Figure 2 shows a representative distribution obtained from 367,000 examinations at 1.5T systems. Resulting core temperature values of examinations with (predicted) SA values $>7 \mathrm{~kJ} / \mathrm{kg}$ are not known and will depend on the length of the examination (long-term RF duty cycle) and the thermoregulatory and heat loss capabilities of the patient. In general, high SA levels can be expected to be uncomfortable, and MRI scanner manufacturers recommend not to exceed the value of $7 \mathrm{~kJ} / \mathrm{kg}$ unless a clinical benefitrisk assessment is made and patient surveillance is in place. On the other hand, no evidence exists that the $0.1 \%$ of examinations with $\mathrm{SA}>10 \mathrm{~kJ} / \mathrm{kg}$ correlate significantly with adverse events.

The lack of large-scale data for core temperature increase in patients calls for additional and well-controlled measurements in routine clinical settings. Such data should include tympanic membrane (pre and post) temperature, patient weight, gender, age, body part examined, ambient temperature, and appropriate dosimetry for SA. Beyond core temperature, several studies report rapidly developing profound sweating, whereas heart rate and blood pressure effects were generally negligible $[14,15]$. Significant but highly variable skin temperature increases have also been reported $([11,15,16,26-28]$ and Table 2$)$, but that data is not considered to constitute an indicator of potential health concerns.

\section{Core Temperature Predictions}

Thermophysiological models can be used to estimate RFinduced core temperature increase as function of SAR and exposure duration. Heat accumulation in the human body heavily depends on ambient temperature and insulation (clothing), as well as thermoregulatory capabilities. In their pioneering work, Adair and Berglund [26, 27, 29] used a 2node model (70 kg man) based on the Stolwijk approach to evaluate core temperature increase as function of whole-body SAR, skin blood flow impairment, ambient temperature, relative humidity, and insulation. Predicted core temperature increases correlate well with experimental data, and a sensitivity analysis provides strong indications that the ambient temperature should be $20-21^{\circ} \mathrm{C}$, air humidity should be kept around $50 \%$, and only light clothing can be tolerated (avoid use of blankets). Under these circumstances, and limiting SA to $10 \mathrm{~kJ} / \mathrm{kg}$, moderate cardiovascular impairment effects can be tolerated without causing a core temperature increase exceeding $1^{\circ} \mathrm{C}$. Adair and Berglund also suggested to keep $\mathrm{SAR}<3 \mathrm{~W} / \mathrm{kg}$ and to limit examination duration to $20 \mathrm{~min}$. Their modeling shows that cool down and recovery time is at least 30 minutes under optimal patient health conditions.

The Stolwijk approach used by Adair and Berglund has been superseded by advanced multinode human models in the context of heat exposure in buildings, cars, and under (occupational) exercise [30,31]. Application of such advanced models to the context of MRI (supine patient in an enclosed space) may be of future interest, once more experimental data is available for core temperature over a large number of patients. In the current situation, the rationale for exposure limits and guidance relies on the Adair and Berglund model. This can be done with quite some confidence, since more recent and more detailed RF exposure modeling studies have confirmed their thermal predictions [32-37]. Children have a 
TABLE 1: Overview of experimental data for core temperature rise in relation to RF exposure in MRI equipment.

\begin{tabular}{|c|c|c|c|c|c|c|}
\hline $\begin{array}{l}\text { Reference and } \\
\text { year of } \\
\text { publication }\end{array}$ & $\begin{array}{l}\text { Number of } \\
\text { Subjects }\end{array}$ & $\begin{array}{l}\text { Exposure } \\
\text { Type }\end{array}$ & Dosimetry & $\begin{array}{l}\text { SAR and } \\
\text { Duration }\end{array}$ & $\begin{array}{c}\text { Max core } \\
\text { temperature } \\
\text { increase }\end{array}$ & $\begin{array}{c}\text { Mean core } \\
\text { temperature increase }\end{array}$ \\
\hline [13] (1986) & 25 patients & $\begin{array}{c}\text { ambient temperature } \\
20-24^{\circ} \mathrm{C} \\
\text { whole body }\end{array}$ & no & $\begin{array}{c}0.5-1.3 \mathrm{~W} / \mathrm{kg} \\
\text { per sequence } \\
40-90 \mathrm{~min}\end{array}$ & $0.6^{\circ} \mathrm{C}$ & \\
\hline \multirow{2}{*}{$\begin{array}{l}\text { [14] (1987) } \\
\text { [11] (1989) }\end{array}$} & 50 patients & $\begin{array}{c}\text { ambient temperature } \\
20-24^{\circ} \mathrm{C} \\
\text { whole body }\end{array}$ & no & $\begin{array}{c}0.6-1 \mathrm{~W} / \mathrm{kg} \text { per } \\
\text { sequence }\end{array}$ & $0.5^{\circ} \mathrm{C}$ & $0.2^{\circ} \mathrm{C}$ \\
\hline & 6 volunteers & whole body & partial & $\begin{array}{l}3-4 \mathrm{~W} / \mathrm{kg} \\
30 \mathrm{~min}\end{array}$ & - & $0^{\circ} \mathrm{C}$ \\
\hline [15] (1994) & 6 volunteers & $\begin{array}{c}\text { ambient temperature } \\
21-23^{\circ} \mathrm{c} \\
\text { whole body }\end{array}$ & yes & $\begin{array}{l}6 \mathrm{~W} / \mathrm{kg} \\
16 \mathrm{~min}\end{array}$ & $>1^{\circ} \mathrm{C}$ & $0.5^{\circ} \mathrm{C}$ \\
\hline [16] (2005) & 6 volunteers & $\begin{array}{c}\text { ambient temperature } \\
31^{\circ} \mathrm{c} \text { (not MRI) }\end{array}$ & yes & $0.5 \mathrm{~W} / \mathrm{kg}$ & $0.4^{\circ} \mathrm{C}$ & $<0.2^{\circ} \mathrm{C}$ \\
\hline [12] (2007) & 700 patients & $\begin{array}{c}\text { hyperthermia } \\
\text { treatment } \\
\text { whole body }\end{array}$ & yes & $\begin{array}{c}3-5 \mathrm{~W} / \mathrm{kg} \\
30-60 \mathrm{~min}\end{array}$ & $>2^{\circ} \mathrm{C}$ & - \\
\hline Table 3 (2000) & 11 volunteers & whole body & yes & $\begin{array}{l}4 \mathrm{~W} / \mathrm{kg} \\
15 \mathrm{~min}\end{array}$ & $0.9^{\circ} \mathrm{C}$ & $0.7^{\circ} \mathrm{C}$ \\
\hline [17] (2011) & 400 children & body, head & no & unknown & $>1^{\circ} \mathrm{C}(2 \%)$ & - \\
\hline [18] (2016) & 25 neonates & body & no & unknown & - & $0^{\circ} \mathrm{C}$ \\
\hline [19] (2016) & 69 patients & head & no & $\begin{array}{l}\text { unknown; } \\
<30 \text { min }\end{array}$ & $>1^{\circ} \mathrm{C}$ & $0.8^{\circ} \mathrm{C}$ \\
\hline
\end{tabular}

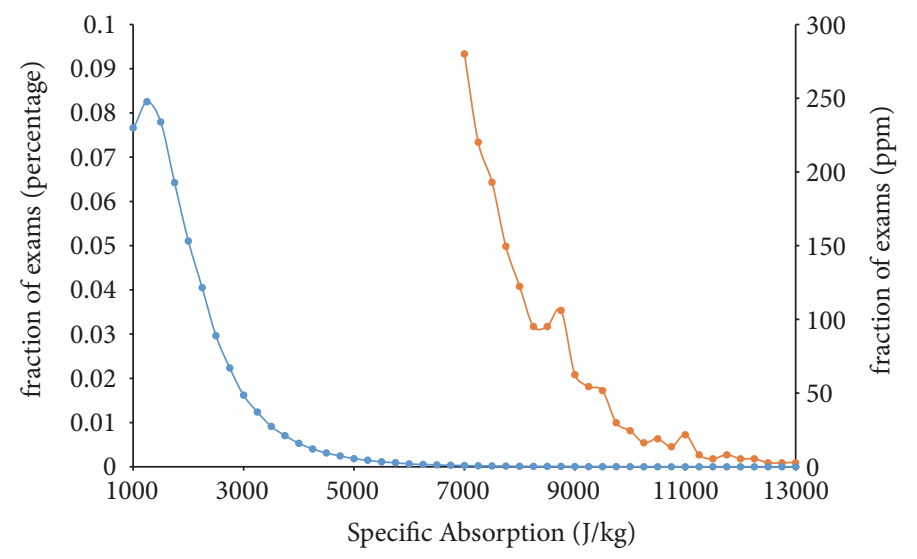

FIgURE 2: Typical distribution of predicted Specific Absorption (SA, in bins of $250 \mathrm{~J} / \mathrm{kg}$ ) observed in clinical use of $1.5 \mathrm{~T}$ MRI examinations for all body parts at multiple hospitals. The blue curve (left axis) shows the percentage of examinations as function of exposure. Less than $10 \%$ of the examinations is performed with SA $>3 \mathrm{~kJ} / \mathrm{kg}$. Use of much higher SA values is, however, not uncommon, as shown by the orange curve (right axis, fraction of examinations in ppm): approx. $1 \%$ of patients are exposed to $>7 \mathrm{~kJ} / \mathrm{kg}$, and $0.1 \%$ to $>10 \mathrm{~kJ} / \mathrm{kg}$.

greater surface-to-volume ratio than adults, and can tolerate approx. 30\% higher whole-body SAR than adults for the same core temperature increase [38].

A simplified parametric approach is suggested in [26] to enable a sensitivity analysis of core temperature increase as function of SAR, skin blood flow impairment, clothing/insulation, ambient temperature, and air humidity. Temperature rise correlates with total deposited energy (SA) and restriction of the allowable SA value was suggested in [39]. Some scenarios of this linearized parametric approach are provided in Figure 3(a) to illustrate the relative importance of the model parameters; for further detailed analyses, refer to $[26,27]$. Notably, the effect of room humidity is not a major factor in addressing systemic heat load concerns whereas room temperature must be kept low. Covering blankets should be avoided, but patients may come in feeling cold. A good recommendation may be to take away any blankets after 10-15 minutes of scanning, or at SED levels $>2-3 \mathrm{~kJ} / \mathrm{kg}$.

Figures 3(b) and 3(c) analyze thermal effects for several scan room conditions, clothing, and selected SAR level. Several representative exposure scenarios are provided for unimpaired (b) and severely impaired (c) skin blood flow. 


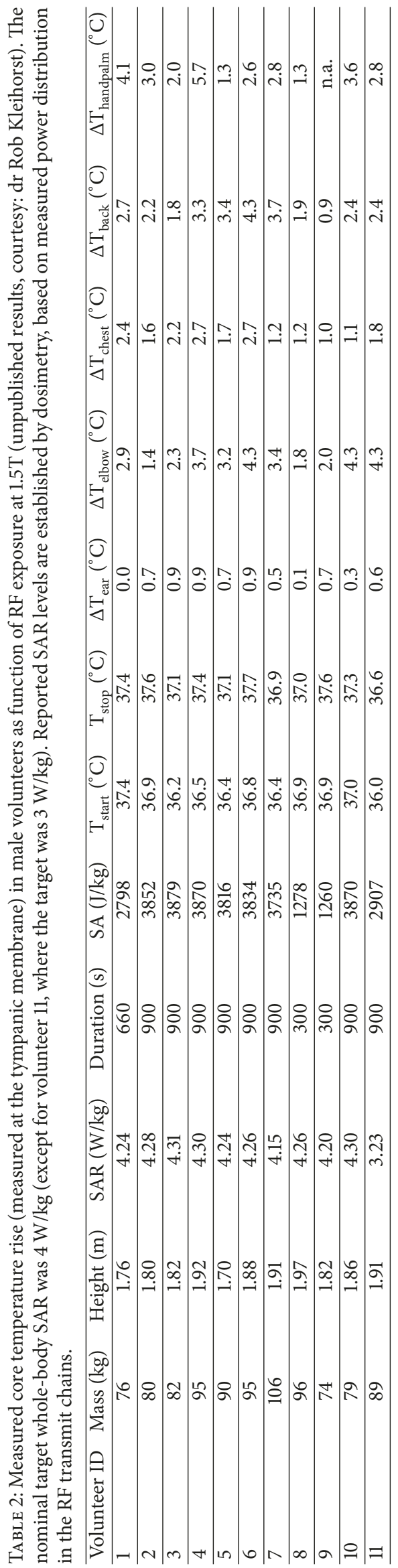




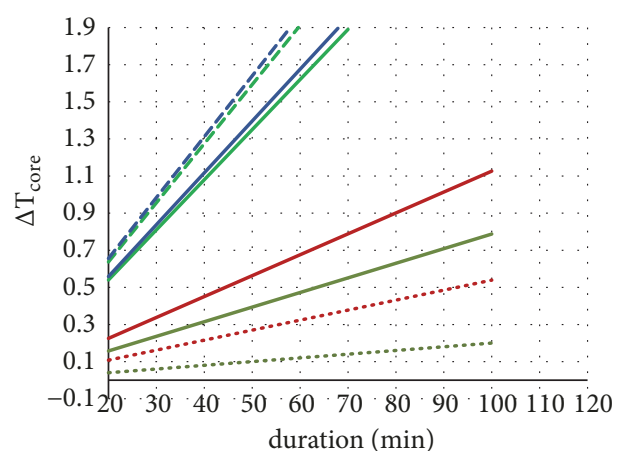

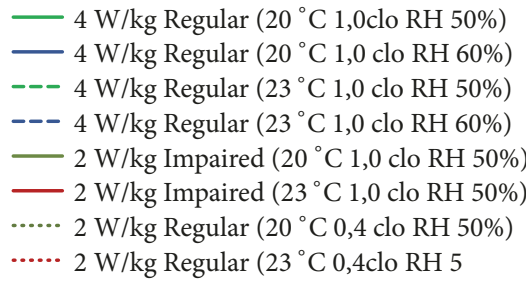

(a) Estimated core temperature increase for a $70 \mathrm{~kg}$ human using the simplified assessment proposed in [26], to demonstrate sensitivity on several model parameters. The lower (orange and red) lines show the significant dependence on room temperature (orange versus red lines), clothing (dotted versus solid lines), and thermoregulatory health of the patient. The upper (blue and green) lines show that room humidity is a less important parameter to control, even at high RF deposition $(4 \mathrm{~W} / \mathrm{kg})$

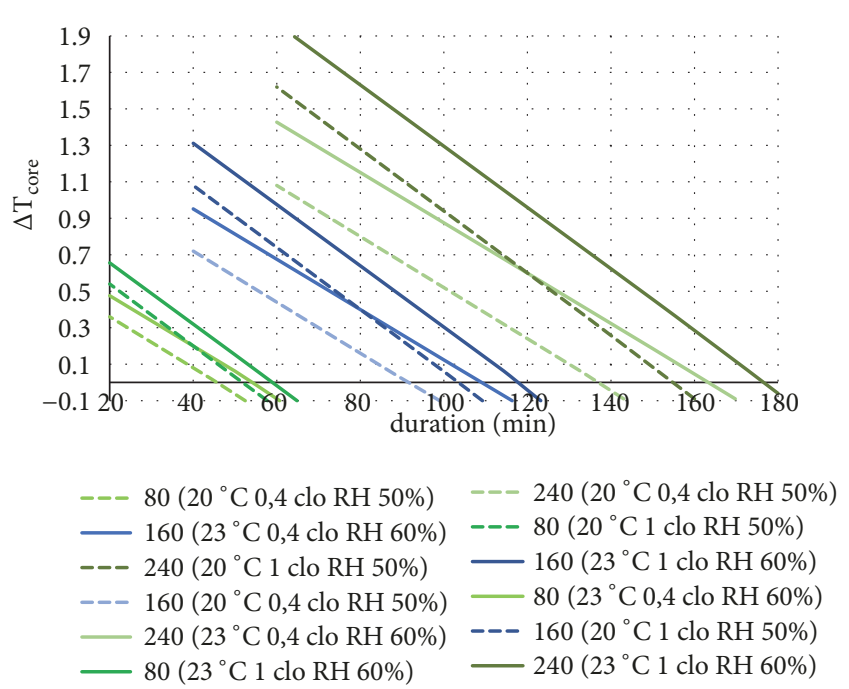

(b) Estimated core temperature increase for a 70kg human with normal thermoregulation [26], at different environmental conditions, and for three levels of Specific Absorption (80, 160, and 240 W.min $/ \mathrm{kg}$ ), up to a SAR level of $4 \mathrm{~W} / \mathrm{kg}$. Each graph represents an iso-SA line, and the corresponding SA value (e.g., 160 W.min/kg for the lowest dashed blue line) divided by the scan or examination duration provides the average whole-body SAR. For example, a duration of $80 \mathrm{~min}$ and $\mathrm{SA}=160 \mathrm{~W} \cdot \mathrm{min} / \mathrm{kg}$ correspond to an average SAR of $2 \mathrm{~W} / \mathrm{kg}$ and a predicted core temperature rise of approx. $0.2^{\circ} \mathrm{C}$. Similarly, a duration of $40 \mathrm{~min}$ on the same line corresponds to an average SAR $4 \mathrm{~W} / \mathrm{kg}$ and a predicted temperature increase of $0.7^{\circ} \mathrm{C}$. Notably, the predictions for SA of $80 \mathrm{~W} . \mathrm{min} / \mathrm{kg}$ correspond reasonably well with the data in Table 1 (estimated 1 clo, room temperature not specified but likely close to $23^{\circ} \mathrm{C}$ )
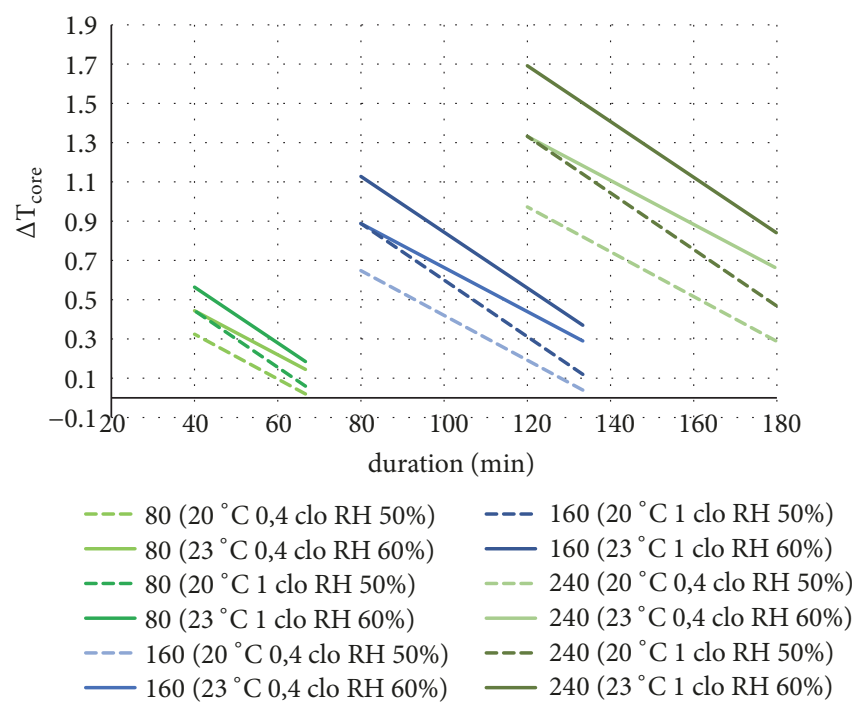

(c) Representative estimates of core temperature increase for a $70 \mathrm{~kg}$ human with impaired thermoregulation, at different environmental conditions, and for three levels of Specific Absorption (80,160, and 240 W.min $/ \mathrm{kg}$ ), up to a SAR level of $2 \mathrm{~W} / \mathrm{kg}$

\section{FIGURE 3}

Three SA levels are evaluated to estimate core temperature rise, viz. $80 \mathrm{~W} . \mathrm{min} / \mathrm{kg}=4.8 \mathrm{~kJ} / \mathrm{kg}, 160 \mathrm{~W} \cdot \mathrm{min} / \mathrm{kg}=9.6 \mathrm{~kJ} / \mathrm{kg}$, and $240 \mathrm{~W} . \mathrm{min} / \mathrm{kg}=14.4 \mathrm{~kJ} / \mathrm{kg}$. Individual lines represent

(i) ambient temperatures of $20^{\circ} \mathrm{C}$ and $23^{\circ} \mathrm{C}$; (ii) light clothing (hospital gown: 0,4 clo) and additional blanket or large surface coils (1.0 clo);

(iii) relative humidity of $50 \%$ at $20^{\circ} \mathrm{C}$ and $60 \%$ at $23^{\circ} \mathrm{C}$. 
Whole-body SAR at each point of the iso-SA line can be calculated as the SA value divided by the time in minutes. The upper left values for each line in Figure 3(a) correspond to 4 $\mathrm{W} / \mathrm{kg}$, which is a highly unlikely long-term average exposure during an MR examination. Worst case examinations with high whole-body SAR and 45-60 min duration are continuous TSE scans for thoracic and lumbar spine, with probably an average value $>3 \mathrm{~W} / \mathrm{kg}$. The graphs in Figure 3(a) show that core temperature increase in thermoregulatory normal people could readily exceed the postulated threshold of $1^{\circ} \mathrm{C}$ and reach up to or exceed $1.4^{\circ} \mathrm{C}$. When thermoregulation is severely compromised, like for diabetics or in case of certain drug regimes, far higher temperature increase can be expected. Patients presenting with such conditions, including fever, should only be scanned in Normal Mode, i.e., wholebody SAR up to $2 \mathrm{~W} / \mathrm{kg}$. IEC 60601-2-33 [2] postulates that core temperature increase should not exceed $0.5^{\circ} \mathrm{C}$ in that case. TSE scans for spine at $2 \mathrm{~W} / \mathrm{kg}$ will take considerably longer duration, examination duration would be prolonged, and SA levels of 120-160 W.min/kg may not be uncommon, corresponding to potential temperature increases of $0.6-0.8^{\circ} \mathrm{C}$; see Figure 3(b) where the top left of the iso-SA curves corresponds with $2 \mathrm{~W} / \mathrm{kg}$. The next section will review thermal thresholds in light of the observed discrepancy between anticipated core temperature increases in actual use in current (safe) MRI practice and restrictions postulated in IEC 60601-2-33.

\section{Thermal Thresholds for Core, Brain, and Eyes}

This section provides an overview of the global thermal thresholds for sensitive internal organs, esp. the brain and the eyes. The temperatures in these organs relate directly to blood temperature and are part of the assessment of systemic burden. Basic restrictions in RF safety standards and guidelines $[1,9]$ aim to limit core temperature, i.e., average blood temperature (rise) [40-42], primarily to prevent functional changes and structural damage in the brain (including the eye), and to avoid a potential overload of thermoregulation capacity (stress to cardiovascular function) [23]. Maintenance of core temperature and protection against thermal insults at cellular and organ levels rely on intricate mechanisms of neuronal and biochemical signaling, for a recent review see [43].

Induced stress includes rapid increase in sweat rate, coupled to skin blood flow and increased cardiac output and a potential decrease in arterial blood pressure [27, 44, 45]. Precise levels for temperatures at which biophysical control mechanisms are activated or may fail are not well established and may vary [46] as function of age, pregnancy, obesity and hypertension, or additional stress factors (e.g., diuretics, tranquillizers and sedatives, vasodilators, and some other drugs, chemotherapy or radiotherapy [47]).

Healthy humans can tolerate core temperature increases $>1^{\circ} \mathrm{C}$ for a few hours, but longer exposure at slightly higher temperatures can lead to serious adverse effects (heat stroke, often associated with severe dehydration). ICNIRP (in the draft update of [1], following [48]) has adopted and reconfirmed the use of $1^{\circ} \mathrm{C}$ as conservative limit for core temperature rise, or "operational adverse health effect threshold", in occupational settings. Higher values can be allowed in a controlled setting when appropriate training is provided for workers with normal health conditions. Since RF exposures during MRI examinations can likely cause a temperature increase $>1^{\circ} \mathrm{C}$, further evaluation of this safety criterion is needed.

Normal core temperature for humans is commonly postulated to be $37^{\circ} \mathrm{C}$ [20] with variations up to $0.5^{\circ} \mathrm{C}$ (mean $0.25^{\circ} \mathrm{C}$ ) by the diurnal cycle. Additional temperature variation up to $0.5^{\circ} \mathrm{C}$ (mean $0.25^{\circ} \mathrm{C}$ ) is associated with the menstrual cycle [49]. A critical review of technology and site of measurement indicates that the mean value is $0.2-0.5^{\circ} \mathrm{C}$ lower than $37^{\circ} \mathrm{C}$ [21]. A diverse cohort study [50] of 35488 patients (mean age 52.9 years, $64 \%$ women, and $41 \%$ nonwhite race) with 243506 temperature measurements reports a mean temperature of $36.6^{\circ} \mathrm{C}\left(95 \%\right.$ range $35.7-37.3^{\circ} \mathrm{C}$; $99 \%$ range $35.3-37.7^{\circ} \mathrm{C}$ ). This range includes effects of the circadian cycle, and will be used in this section to assess if additional margin can be allowed for the commonly adopted limit of $1^{\circ} \mathrm{C}$ for core temperature increase for MRI exposures.

Preventing harm from core temperature increase relies on two arguments [9, 23, 40]: (1) effects on the Central Nervous System (CNS) and induced permeability of the Blood Brain Barrier (BBB) and (2) heat exhaustion and behavioral aversion. Figure 4 summarizes human core and brain temperature and its variation, in relation to these guiding principles. In the subsequent paragraphs, both arguments are discussed in more detail.

Argument 1. Limits to core or blood temperature intend to prevent indirect (additional) heating of internal organs, esp. the brain. Note the presence of an approx. $1^{\circ} \mathrm{C}$ temperature gradient in the brain, where the surface temperature, e.g., at the tympanic membrane, equals core (blood) temperature [51]. The average and deep brain temperatures are 0.5 to $1.0^{\circ} \mathrm{C}$ higher than core temperature due to the intense metabolic activity in gray matter (activation of the visual cortex is reported to locally increase its temperature by $0.7^{\circ} \mathrm{C}$ [51]). Arterial blood and CSF provide the necessary cooling capacity to maintain homeostasis. Even higher temperatures can be caused by certain drugs or neurologic diseases $[24,52]$.

MRI systems intentionally expose patients to high RF amplitude and dose, generally for a short duration, i.e., less than 1 hour. Such exposures must be controlled to avoid "physiological stress", defined as occurrence of effects beyond modest discomfort. Control mechanisms include considerations of transient effects [53-56], and local effects; see section on thermal dose. The requirement that diagnostic imaging procedures shall not invoke undue stress is different from limits based on benefit-to-risk considerations which are used in treatments like (RF) hyperthermia, where occasional side effects could be acceptable when treating a known serious health risk [12, 57-59]. The onset of (severe) sweating and the additional load of the cardiovascular system related to thermoregulatory response may, however, need to be avoided in certain patient groups $[27,44,45]$. The whole-body SAR limit for Normal Operating Mode in IEC 60601-2-33 [2] is therefore set to $2 \mathrm{~W} / \mathrm{kg}$. Simulations indicate that no special provisions are needed for elderly people, since the estimated 


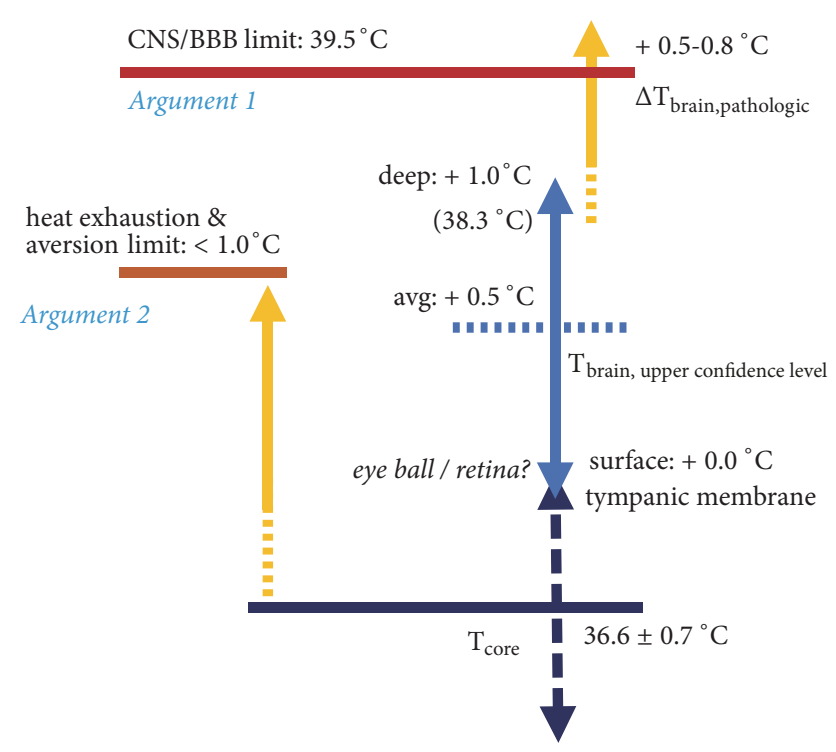

FIGURE 4: Overview of body temperature data for adults and their relation to allowable temperature increase from RF exposure.

effect of aging is less than variations in core temperature increase associated with other factors $[32,35]$.

ICNIRP proposes to limit temperature increase for the brain (incl. the eye) conservatively to $2^{\circ} \mathrm{C}$ for occupational settings (in the $2018 \mathrm{draft}$ of [1]). Such temperature increases, however, cannot be justified in case of brain injury, such as stroke or TBI, where modest temperature increases have been reported to adversely affect outcomes [24, 60, 61]. Similar caution is needed for cerebral disease or drugs regimes where brain temperatures are elevated $[49,52]$.

Limited experimental data from animal models indicates that functional abnormalities of the CNS, and $\mathrm{BBB}$ disruption are initiated at temperatures of $39-39.5^{\circ} \mathrm{C}[52,62]$. Effects on brain function and tissue seem reversible in case of short duration temperature elevation, and an upper limit of $39.5^{\circ} \mathrm{C}$ for maximum (deep) brain temperature seems sufficiently conservative. Taking into account the temperature allowance necessary to account for possibly unknown pathologic brain conditions, and at maximum core temperature levels, deep brain temperature without $\mathrm{RF}$ exposure may reach $38.8^{\circ} \mathrm{C}$. Consequently an increase of $0.6-0.7^{\circ} \mathrm{C}$ is deemed acceptable for vulnerable patients. IEC 60601-2-33 requires to scan such patients in Normal Mode, with reduced RF output and clinical observation. Figure 3(b) indicates that under such conditions the temperature increase will indeed not exceed these limits. Temperature in patients with normal thermoregulation will be considerably (at least $0.7^{\circ} \mathrm{C}$ ) lower than $38.8^{\circ} \mathrm{C}$, and $1.3-1.4^{\circ} \mathrm{C}$ core temperature increase can be considered acceptable. This value is predicted in Figure 3(a) for long examination high-SAR scans (in First Level Controlled Operating Mode) and is consistent with the history of safe use of MRI.

Thermal sensitivity of the eye is inherently linked to thermal limits for systemic protection, because temperature of the eye is largely determined by arterial blood temperature. Corneal temperature is approx. $3^{\circ} \mathrm{C}$ lower than core temperature $[63,64]$. Cataract formation is reported in rabbits for $20-40 \mathrm{~W} / \mathrm{kg}$ local SAR at the eye; absence of such effects at these SAR levels in monkeys is attributed to differences in skull and eye anatomy [65]. Lesions were also detected in isolated bovine eyes [66] for incidental exposure to temperatures $>39^{\circ} \mathrm{C}$. Damage of the bovine lenses was recoverable when exposed $1 \mathrm{~h}$ to $39.5^{\circ} \mathrm{C}$ but remained in the lens epithelial cells. Experimental data report temperature increases of the cornea $<1.8^{\circ} \mathrm{C}$ in 33 patients at $\mathrm{RF}$ exposures of $3 \mathrm{~W} / \mathrm{kg}$ head SAR [67], which is of no concern given the low basal temperature of the lens [63]. Such increase is consistent with numerical simulation results predicting a temperature increase $>1^{\circ} \mathrm{C}$ in the eye when applying 3.2 $\mathrm{W} / \mathrm{kg}$ head SAR for $30 \mathrm{~min}[68,69]$. Local-to-head SAR ratio in quadrature RF excitations is approx. $4[55,70]$, and 3.2 W/kg head SAR corresponds to a local SAR exposure of 10-13 $\mathrm{W} / \mathrm{kg}$, or $<1^{\circ} \mathrm{C}$ temperature increase in brain tissue $[71,72]$. Note that $3.2 \mathrm{~W} / \mathrm{kg}$ head SAR applies to both Normal Mode and First Level Mode in IEC60601-2-33 and is inconsistent with different local SAR limits for those modes (10 and 20 $\mathrm{W} / \mathrm{kg}$, respectively). The local SAR hotspot for quadrature excitation does not coincide with the eye, and in that case no temperature concerns are present; this is different for parallel transmit, RF-shimmed excitations [69]. Specific attention is needed to prevent temperature increase in the eye for localized transmit or parallel transmit scenarios where RF energy is focused in the eye area [71]. Steering of local SAR by RF pulse design and averaging of RF deposition by multiple shimmed RF pulses can be used to mitigate such high local SAR hotspots, especially at ultra-high field and multichannel parallel transmit systems [71]. Exposure to higher levels of local SAR $(20 \mathrm{~W} / \mathrm{kg}, 0.56 \mathrm{CEM} 43)$ in the context of RF hyperthermia in oncology patients did not reveal cataract formation [73].

Argument 2. Thermally induced task aversion resulting from $4 \mathrm{~W} / \mathrm{kg}$ RF exposure has been reported in animals [9]. Similarly, humans will adapt their behavior in warm environments to avoid heat stroke. Studies in healthy volunteers have shown significant adverse effects when exposed to core temperatures approaching $39^{\circ} \mathrm{C}$ as a result of severe exercising $[9,25,74]$. Effects of temperature and dehydration cannot be separated in such studies. There is a broad consensus that avoidance of undue heat stress in healthy humans requires core temperature to stay below $38.5^{\circ} \mathrm{C}$ (measured at the tympanic membrane) and should likely be less in vulnerable humans. This value is consistent with an allowable increase of $1.3-1.4^{\circ} \mathrm{C}$ beyond the highest reported core temperature in nonfebrile patients $\left(37.3^{\circ} \mathrm{C},[50]\right)$.

\section{Thermal Protection of the Fetus}

Episodes of high temperature in the embryonic stage can be teratogenic or can result in developmental defects [75]. A retrospective review supported concerns for potential negative health impact associated with first trimester fever in humans [76]. To the contrary, a subsequent large-scale prospective study by the same authors concludes that there is no evidence that maternal fever during pregnancy induces congenital defects [77]. The latter finding corroborates reports that 
(noncontrast enhanced) MRI during pregnancy does not negatively impact childhood outcomes $[78,79]$.

MRI scanning was likely performed using Normal Mode ( $2 \mathrm{~W} / \mathrm{kg}$ whole-body SAR), as required by IEC 60601-2-33 in case of pregnancy; see also [80]. Alternatively, a level of $1.5 \mathrm{~W} / \mathrm{kg}$ for up to 1 hour scanning is suggested as limit for 2nd and 3rd trimester in [75]. Obstetrician's guidelines also suggest to defer scanning, if any, to after the first trimester [81]. This is in line with consensus guidelines for fetal ultrasound [6, 7], which aim for As Low As Reasonable Achievable (ALARA) risk by limiting thermal dose to the fetus to 1 CEM43 (see below).

Fetal temperature is $0.3-0.5^{\circ} \mathrm{C}$ above maternal core temperature [82-84], and heat exchange depends almost completely on the umbilical cord and placental heat exchange. Numerical simulations of $80 \mathrm{MHz}$ plane wave exposure show that (average) fetal temperature increase may exceed that of the mother [85], with values of $0.4-0.8^{\circ} \mathrm{C}$ for $1 \mathrm{hr}$ at $2-4$ $\mathrm{W} / \mathrm{kg}$ whole-body SAR in the mother. Similar values have been reported for 1 hour MRI exposures in Normal Mode $(1.5-2 \mathrm{~W} / \mathrm{kg})$ in $[80,82,84]$. These predicted increases will keep the average temperature in the fetus below $38^{\circ} \mathrm{C}$. Highresolution numerical modeling indicates the existence of local thermal hotspots in the fetus and the placenta [84], similar to inhomogeneous local SAR and temperature distributions in adults $[53,55,86-90]$. Hotspots in the fetus may be particularly enhanced in case of unfavorable RF shimming conditions at 3T [84], where image quality optimization $\left(\mathrm{B}_{1}^{+}\right.$ homogenization) in the mother may unduly increase the RF load in the fetus. The use of quadrature RF excitation, or circularly polarized (CP) mode, is therefore recommended, at the expense of uniform flip angle distribution. Note that frequent fetal movements are expected to reduce the severity of local SAR and temperature hotspots in the fetus, but not in the placenta. Short duration, low SAR, CP mode scanning should remain the guidance for MRI in pregnancy.

\section{Thermal Dose and Its Proposed Used in MRI}

Globally uniform RF transmit fields, such as CP in birdcage volume transmit coils, lead to a highly nonuniform local SAR distribution in the human body [91]. Early attempts aimed to reflect this effect by using partial-body SAR instead of whole-body SAR, but simulations have shown that this approach allows for higher RF duty cycles and thereby even higher local SAR $[92,93]$. Local SAR hotspots may cause local temperature rise, which may, at least in patients with sufficient thermoregulatory response, be moderated by thermal diffusion and (increasing) blood flow. An overview of the biophysical aspects connecting SAR and local temperature is given in [94], where it is argued that vasodilation may not be effective for localized exposures. Numerical electromagnetic simulations provide local SAR values which can be used in combination with Pennes' Bioheat Equation (PBE) to derive temperature distributions with an acclaimed accuracy of 10$15 \%[53,55,71,86-90,95]$. A more advanced model, the Generic Bioheat Transfer Model, was proposed to better fit data obtained on anesthetized swine [96] and addresses issues related to the assumption of constant blood temperature in PBE. Lack of experimental data in humans and variability of human anatomy and physiology make it virtually impossible to decide which model is more appropriate. Required accuracy for local SAR and temperature simulations with respect to averaging volume (1g versus $10 \mathrm{~g}[97,98]$ ), averaging scheme $[1,72,99]$, and number of required tissue types is discussed in [97]. The use of steady-state approaches clearly overestimates the initial thermal response (15 minutes), since energy deposition can under normal circumstances first be redistributed in the peripheral body parts [94]. A critical review of the merits and implications of the use of $\mathrm{PBE}$ concludes that it is adequate in the context of RF-induced heating simulations [100]. This modeling approach has been validated with measurements in RF hyperthermia [101], for local exposure at 7T [102], and in (anesthetized) pigs where severe muscle damage was observed for $>4 \mathrm{~W} / \mathrm{kg}$ and SA of $8-15 \mathrm{~kJ} / \mathrm{kg}$ [103]. The observed damage in [103] points to the usefulness of applying the thermal dose concept, or CEM43, from hyperthermia to assess potential risks associated with long-term high-SAR MRI examinations.

CEM43, or cumulative equivalent minutes at $43^{\circ} \mathrm{C}$, is a local thermal dose "iso-effect" metric [3], representing the duration of exposure at a reference temperature of $43^{\circ} \mathrm{C}$, associated with the magnitude of a thermally induced bioeffect observed or predicted to occur at a different temperature $\mathrm{T}$ for duration $\mathrm{t}_{\text {exam. }}$. The actual temperature $\mathrm{T}$ may vary as function of time. In this context, 10 CEM43 represents 10 min of exposure at $43^{\circ} \mathrm{C}$. The CEM43 model approximates the nonlinear relationship of tissue damage by using two loglinear relationships with a break point at $43^{\circ} \mathrm{C}$ :

$$
\text { CEM43 }=\int_{0}^{t_{\text {exam }}} R^{k(T(\tau)-43)} \mathrm{d} \tau
$$

where

$$
\begin{aligned}
& \mathrm{k}=\left(1^{\circ} \mathrm{C}\right)^{-1} \text {, a constant to render the exponent dimen- } \\
& \text { sionless; } \\
& \mathrm{T}(\tau)=\text { temperature during time course } \tau \text { of an MRI } \\
& \text { examination; } \\
& \tau=\text { time; } \\
& \mathrm{t}_{\text {exam }}=\text { duration of the MRI examination, incl. addi- } \\
& \text { tional integration time after the last } \mathrm{RF} \text { exposure to } \\
& \text { account for temperature normalization; } \\
& \mathrm{R}=\text { exponential constant, } 0.25 \text { for } \mathrm{T}<43^{\circ} \mathrm{C} \text { and } 0.5 \\
& \text { for } \mathrm{T} \geq 43^{\circ} \mathrm{C} \text {. }
\end{aligned}
$$

Validity of CEM43 as a metric to assess treatment effects and risk to damage surrounding tissue is generally accepted for temperatures in the range of $39^{\circ} \mathrm{C}$ and $57^{\circ} \mathrm{C}$ [104]. Note, however, that CEM43 is based on Arrhenius plot for counted death cells, while the onset of detectable death cells is not immediate. A more accurate parameter to describe absence of risk would be the fraction of living cells, which involves higher-order biochemical feedback paths [105]. CEM43 is considered to overpredict tissue damage risk at moderate temperature elevations [4], which can be considered adequate to establish safety in MRI as it adds conservativeness in 
protection against damage. The delay of observable damage [105] may, however, indicate a risk of unnoticed thermal overburden during the MRI examination.

The exponential constant $\mathrm{R}$ is determined from cell cultures and animal models [104]; human data is scarce but indicates that the $\mathrm{R}$-values in human tissue may reflect a higher thermal tolerance. Using the established R-values of 0.25 and 0.5 provides a more conservative accumulation of CEM43, and thresholds for basic restrictions have also been derived based on these values for $\mathrm{R}[8,104]$. Thresholds vary by more than two orders of magnitude with animal species and tissue type, and an analysis of lowest value with reported damage, and highest value with no reported damage is provided in [8]. A conservative threshold of 2 CEM43 is proposed for all tissues and all patients. Higher values (9 CEM43 and 15 CEM43) are suggested to be safe for skin, muscle, fat, and bone. The ultrasound community has used the same information to derive a limit value of 1 CEM43, but acknowledges that 2 CEM43 would also be acceptable $[7,75]$. This threshold will protect nerves, both in the spinal cord and embedded in muscle. Peripheral nerves are reported to be particularly vulnerable in sensitive patient classes, such as those with diabetes or Multiple Sclerosis and those undergoing chemo- or radiotherapy [106, 107].

CEM43 can be calculated from local SAR values (averaged over $10 \mathrm{~g}$ of tissue, psSAR10g) [108]. Peak temperature increase and thermal time constants were obtained for six numerical human models at different imaging positions at $1.5 \mathrm{~T}$ and $3 \mathrm{~T}[86,88,89]$, under the conditions of thermoregulation, and for basal perfusion. Extension to impaired thermoregulation is provided in [90], with an update of the parameters to be used in the model. Temperature increase is calculated as a function of the value of psSAR10g for the voxel where local SAR is highest [108]. Using an estimated baseline temperature (for example, $36.8^{\circ} \mathrm{C}$ or $38^{\circ} \mathrm{C}$ ), a worst case estimate for CEM43 is obtained, albeit that effects of core temperature increase are not accounted for. A reevaluation of the results of [108] seems warranted since core temperature increase could add $20-25 \%$ to the temperature increase caused by local SAR. Another necessary extension of [108] relates to local exposure scenarios, using detachable transmit coils for head and knee imaging, as well as for cardiac and prostate imaging at 7T. Specific parameters are needed to derive temperature increase from (maximum) local SAR in such use cases.

Worst case CEM43 values were calculated [108] for the exposure scenario where local SAR limits from IEC 60601-233 are applied to whole-body RF excitation. The calculated thermal dose values are based on predicted local SAR values from the Philips MR system software. Figure 5 shows a correlation of calculated CEM43 and predicted Specific Absorption for 6500 body/torso exams with SA between 4 and $11 \mathrm{~kJ} / \mathrm{kg}$ (subset of data used for Figure 2), using a baseline temperature of $37^{\circ} \mathrm{C}$ and assuming that either all patients have fully regulated perfusion or all patients present with severely impaired thermoregulation. High SA levels will only be reached for landmarks between neck and groin (wholebody SAR is lower for other landmarks). Considering that Local Torso SAR is limited to $20 \mathrm{~W} / \mathrm{kg}$, thermal dose will not exceed 1 CEM43 in examinations of the torso. In other words, high SA does not directly correlate with high local thermal dose. Higher CEM43 values may be reached for landmarks where the ratio local SAR to whole-body SAR is higher. Figure 6 provides an overview of 210,000 examinations at $1.5 \mathrm{~T}$ and 3.0 $\mathrm{T}$ to assess the predicted temperature distribution and the resulting likelihood of high CEM43 values, under conditions of normal and compromised thermoregulation. Under the assumptions used in [108] (heavy patient, worst case hotspot, and basal temperature $37^{\circ} \mathrm{C}$ at any tissue), it can be inferred that less than 1 in 10000 patients would be exposed to thermal dose $>2$ CEM43. Note that this predicted thermal dose value will overestimate thermal dose in most patients due to assumptions in [108]. The values shown in Figure 6 cannot be used to establish limits based on history of safe use' arguments. Validation of temperatures and thermal dose values requires further investigation before safe thresholds can be established.

High local thermal dose is delivered on purpose in RF hyperthermia, where acute adverse effects (pain and RF burns) are reported for high local SAR (100 W/kg and higher) $[12,59]$. Where [12] uses their observation that $1 \%$ of $(700)$ patients in 3000 treatment sessions showed burns to propose safe local SAR limits for MRI at $20 \mathrm{~W} / \mathrm{kg}$ for head, neck, and torso and $30 \mathrm{~W} / \mathrm{kg}$ for the extremities, the results from [59] and other literature data [104] are used in [109] to derive the lowest thermal dose (TD) required to induce acute local tissue damage and to calculate the corresponding TDfunctional SAR limits $\left(\mathrm{SAR}_{\mathrm{TDFL}}\right)$ for a $10 \mathrm{~min}$ and a $60 \mathrm{~min}$ steady-state exposure. CEM43 restrictions can be realized by applying appropriate $\mathrm{SAR}_{\mathrm{TDFL}}$ limits to whole-body transmit coils, in conjunction with limits for whole-body SAR or head SAR. Using the thermal damage threshold for muscle (60 CEM43), [109] suggests that a SAR $\mathrm{TDFL}_{\text {of }} 200-300 \mathrm{~W} / \mathrm{kg}$ could be tolerable. Current local SAR limits in IEC 60601$2-33$ are $5-10 \mathrm{x}$ lower $(20 \mathrm{~W} / \mathrm{kg}$ in the trunk and $40 \mathrm{~W} / \mathrm{kg}$ in the extremities). Preliminary analysis of CEM43 'big data' indicates that 2 CEM 43 corresponds with current limit values for local SAR in IEC 60601-2-33 (Figure 6), but that higher values could occasionally occur. Such higher values have been suggested previously to be safe based on an extensive review of CEM43 data [8], but evidence is insufficient to adopt thermal dose thresholds $>2$ CEM43. Further studies are necessary to establish the appropriate model to evaluate CEM43 and conservative values for CEM43 limits in brain and lower extremities esp. when using detachable transmit knee coils and for 7T where local excitation coils are commonly used. These used scenarios are insufficiently covered in [108], but their methodology can be used to assess potential thermal risks in such designs.

\section{Summary}

Protecting patients undergoing MRI examinations from adverse thermal effects necessitates considering both systemic and local temperature increase and thermal dose. Long high-SAR examinations can cause a core temperature increase $>1^{\circ} \mathrm{C}$, which is generally not problematic given normal body temperatures, thermoregulatory capabilities, 


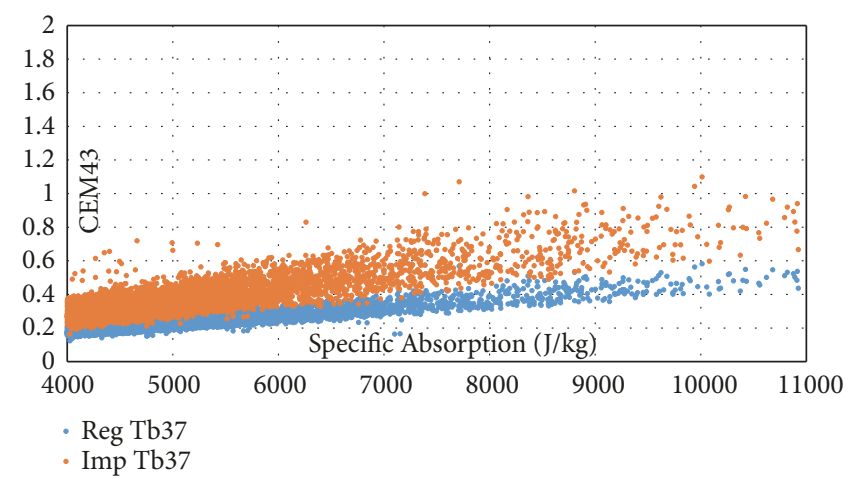

FIgURE 5: Scatter plot of CEM43 and Specific Absorption (SA) for 6500 examinations at 1.5T (out of 367,000 examinations in Figure 2), with SAR limited to local torso level of $20 \mathrm{~W} / \mathrm{kg}[2]$.

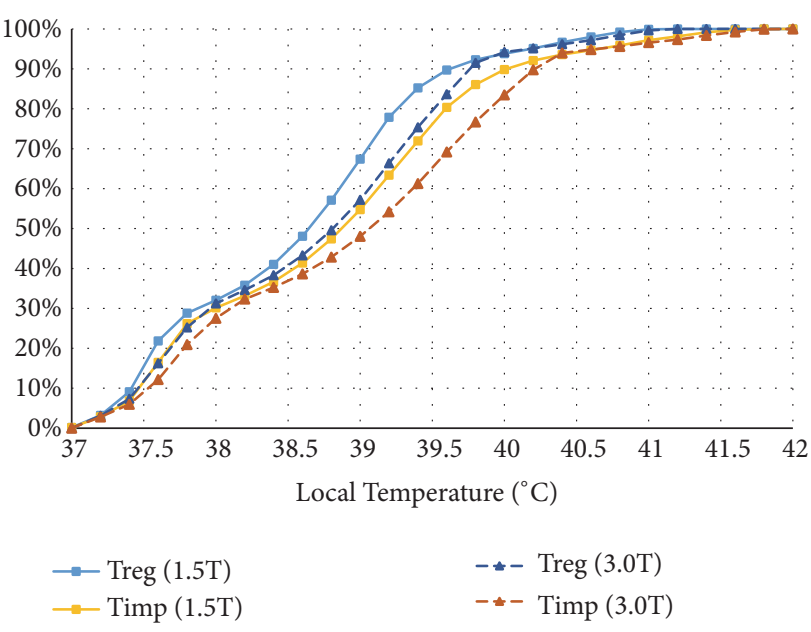

(a)

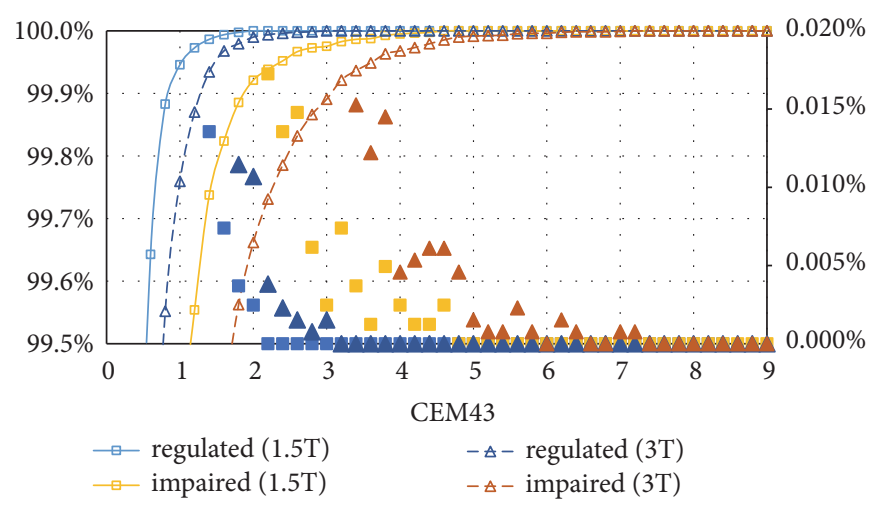

(b)

FIgure 6: Typical distribution of (a) predicted hotspot temperature and (b) CEM43 (in bins of 0.2) observed in clinical use of 210,000 examinations at $1.5 \mathrm{~T}$ and $3 \mathrm{~T}$ MRI for all body parts at multiple hospitals. The blue and orange curves represent normal and impaired thermoregulation starting from a basal temperature of $37^{\circ} \mathrm{C}$ [108] and show the percentage of examinations where a certain CEM43 is calculated. The fraction of high CEM43 values for each bin and each condition is represented as unconnected data points with values shown at the right-side axis. Note that assumed impaired thermoregulation shifts the curves to higher CEM43 values, but such values may be a significant overestimate due to model assumptions.

and allowable brain temperature. To prevent excessive core temperature increase $\left(>1.3^{\circ} \mathrm{C}\right)$, the temperature in the MRI system should be kept below $22^{\circ} \mathrm{C}$, the use of blankets should be avoided, or blankets should be removed after a few initial scans, and actual-delivered Specific Absorption should not exceed $4 \mathrm{~kJ} / \mathrm{kg}$. If higher SA levels are necessary, active cooling of the patient by air flow and medical supervision is warranted to prevent serious discomfort. Lower whole-body SAR $(<2 \mathrm{~W} / \mathrm{kg})$ and short duration examinations should be employed in vulnerable patient groups, including pregnant women. Local SAR control $(<20 \mathrm{~W} / \mathrm{kg})$ for torso and spine examinations is in most cases sufficient to prevent exceeding 2 CEM43 if core temperature increase is not considered. Further studies are needed to account for core temperature increase when calculating CEM43 and to establish appropriate CEM43 limits and evaluation models for exposure of the brain and lower extremities, especially when using detachable transmit coils.

\section{Appendix}

\section{Search Methodology in Embase and Pubmed}

This section provides the search approaches used to identify relevant papers describing thermophysiological effects from $\mathrm{RF}$ exposure in the $10-300 \mathrm{MHz}$ range. Searches were performed in September 2018, and notifications for new papers initiated.

In Embase, the searches and exclusions provided in Table 3 are added sequentially. Note that the "advanced search" option is used as starting point, where all mapping options are disabled, except for searching as free text in all fields.

A similar approach with a few additional exclusion items was applied in Pubmed; see Table 4. Manual rejection of papers was additionally required and based on titles and abstracts. 


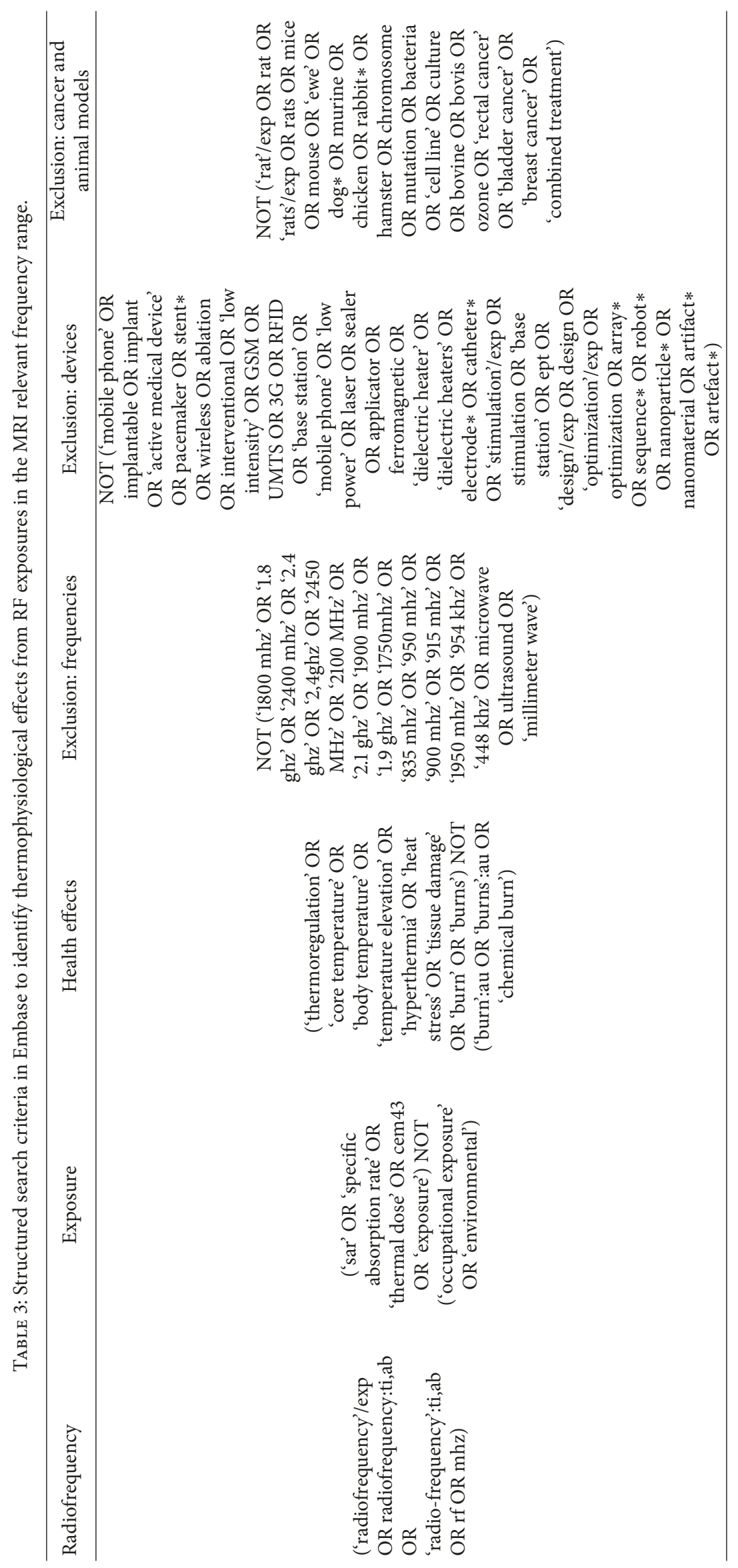




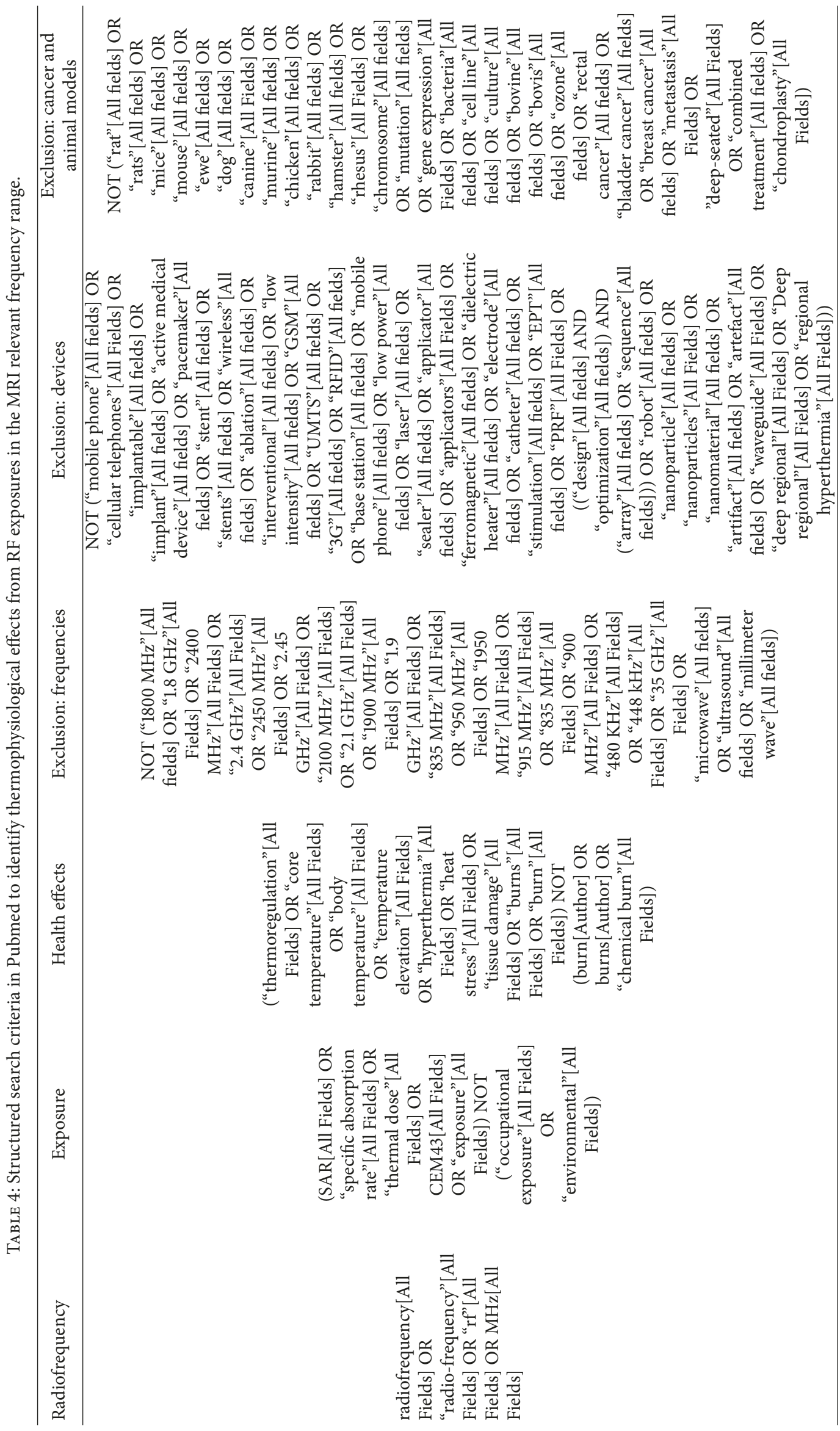




\section{Conflicts of Interest}

Johan S. van den Brink is an employer of Philips.

\section{Acknowledgments}

This work was funded by the EUREKA cluster programme, ITEA3 project STARLIT (16016), and PENTA project DISPERSE (16012).

\section{References}

[1] ICNIRP, "Guidelines for limiting exposure to time-varying electric, magnetic and electromagnetic fields (up to $300 \mathrm{Ghz}$ )," https:/www.icnirp.org/cms/upload/publications/ICNIRPemfgdl .pdf, 2019.

[2] IEC 60601-2-33 Edition 3 Amendment 2, Particular Requirements for The Basic Safety and Essential Performance of Magnetic Resonance Equipment for Medical Diagnosis, Geneva, Switzerland, 2015, https://webstore.iec.ch/publication/22705.

[3] D. A. Sapareto and W. C. Dewey, "Thermal dose determinations in cancer therapy," International Journal of Radiation Oncology, vol. 10, pp. 787-800, 1984.

[4] W. D. O'Brien Jr., C. X. Deng, G. R. Harris et al., "The risk of exposure to diagnostic ultrasound in postnatal subjects: Thermal effects," Journal of Ultrasound in Medicine, vol. 27, no. 4, pp. 517-535, 2008.

[5] IEC TR 62799, Models for Evaluation of Thermal Hazard in Medical Diagnostic Ultrasonic Fields, Geneva, Switzerland, 2013.

[6] M. C. Ziskin, "The thermal dose index," Journal of Ultrasound in Medicine, vol. 29, no. 10, pp. 1475-1479, 2010.

[7] G. R. Harris, C. C. Church, D. Dalecki, M. C. Ziskin, and J. E. Bagley, "Comparison of thermal safety practice guidelines for diagnostic ultrasound exposures," Ultrasound in Medicine \& Biology, vol. 42, no. 2, pp. 345-357, 2016.

[8] G. C. Van Rhoon, T. Samaras, P. S. Yarmolenko, M. W. Dewhirst, E. Neufeld, and N. Kuster, "CEM $43^{\circ} \mathrm{C}$ thermal dose thresholds: A potential guide for magnetic resonance radiofrequency exposure levels?” European Radiology, vol. 23, no. 8, pp. 2215-2227, 2013.

[9] "IEEE Standard C95.1 for Safety Levels with Respect to Human Exposure to Radio Frequency Electromagnetic Fields, $3 \mathrm{kHz}$ to $300 \mathrm{GHz}, 2005$.

[10] ISO 8996:2004, "Ergonomics of the thermal environment Determination of metabolic rate," http://www.deparisnet.be/ chaleur/Normes/Malchaire_iso8996_metabolic_rate.pdf, 2019.

[11] F. G. Shellock, D. J. Schaefer, and J. V. Crues, "Alterations in body and skin temperatures caused by magnetic resonance imaging: is the recommended exposure for radio frequency radiation too conservative?" The British Journal of Radiology, vol. 62, pp. 902909, 1989

[12] P. Wust, J. Nadobny, M. Szimtenings, E. Stetter, and J. Gellermann, "Implications of clinical RF hyperthermia on protection limits in the RF range," Health Physics Journal, vol. 92, no. 6, pp. 565-573, 2007.

[13] F. G. Shellock, D. J. Schaefer, W. Grundfest, and J. V. Crues, "Thermal effects of high-field (1.5 tesla) magnetic resonance imaging of the spine. Clinical experience above a specific absorption rate of $0.4 \mathrm{~W} / \mathrm{kg}$., Acta Radiologica, vol. 369, pp. 514-516, 1986.
[14] F. G. Shellock and J. V. Crues, "Temperature, heart rate, and blood pressure changes associated with clinical MR imaging at 1.5 T,' Radiology, vol. 163, no. 1, pp. 259-262, 1987.

[15] F. G. Shellock, D. J. Schaefer, and E. Kanal, "Physiologic responses to an MR imaging procedure performed at a specific absorption rate of 6.0 W/kg," Radiology, vol. 192, no. 3, pp. 865$868,1994$.

[16] E. R. Adair, D. W. Blick, S. J. Allen, K. S. Mylacraine, J. M. Ziriax, and D. M. Scholl, "Thermophysiological responses of human volunteers to whole body RF exposure at $220 \mathrm{MHz}$," Bioelectromagnetics, vol. 26, no. 6, pp. 448-461, 2005.

[17] D. L. Isaacson, D. J. Yanosky, R. A. Jones, N. Dennehy, P. Spandorfer, and A. L. Baxter, "Effect of MRI strength and propofol sedation on pediatric core temperature change," Journal of Magnetic Resonance Imaging, vol. 33, no. 4, pp. 950-956, 2011.

[18] P. Cawley, K. Few, R. Greenwood et al., "Does magnetic resonance brain scanning at 3.0 tesla pose a hyperthermic challenge to term neonates?" Journal of Pediatrics, vol. 175, pp. 228-230, 2016.

[19] M. S. Kim, "Investigation of factors affecting body temperature changes during routine clinical head magnetic resonance imaging," Iranian Journal of Radiology, vol. 13, no. 4, Article ID e34016, 2016.

[20] V. E. Del Bene, “Temperature (Ch 218)," in Clinical Methods: The History, Physical, and Laboratory Examinations, H. K. Walker, W. D. Hall, and J. W. Hurst, Eds., pp. 990-993, Boston (Butterworths), 3rd edition, 1990.

[21] G. Kelly, "Body temperature variability (part 1): a review of the history of body temperature and its variability due to site selection, biological rhythms, fitness, and aging," Alternative Medicine Review, vol. 11, no. 4, pp. 278-293, 2006.

[22] L. McIlvoy, "Comparison of brain temperature to core temperature: A review of the literature," Journal of Neuroscience Nursing, vol. 36, no. 1, pp. 23-31, 2004.

[23] W. P. Cheshire, "Thermoregulatory disorders and illness related to heat and cold stress," Autonomic Neuroscience: Basic and Clinical, vol. 196, pp. 91-104, 2016.

[24] C. Childs and K. W. Lunn, "Clinical review: Brain-body temperature differences in adults with severe traumatic brain injury," Critical Care, vol. 17, no. 2, article no. 222, 2013.

[25] C. L. Lim, C. Byrne, and J. K. Lee, "Human thermoregulation and measurement of body temperature in exercise and clinical settings," Annals Academy of Medicine Singapore, vol. 37, pp. 347-353, 2008.

[26] E. R. Adair and L. G. Berglund, "Thermoregulatory consequences of cardiovascular impairment during NMR imaging in warm/humid environments," Magnetic Resonance Imaging, vol. 7, no. 1, pp. 25-37, 1989.

[27] E. R. Adair and L. G. Berglund, "Predicted thermophysiological responses of humans to MRI fields," Annals of the New York Academy of Sciences, vol. 649, no. 1, pp. 188-200, 1992.

[28] A. Boss, H. Graf, A. Berger et al., "Tissue warming and regulatory responses induced by radio frequency energy deposition on a whole-body 3-Tesla magnetic resonance imager," Journal of Magnetic Resonance Imaging, vol. 26, no. 5, pp. 1334-1339, 2007.

[29] E. R. Adair and L. G. Berglund, "On the thermoregulatory consequences of NMR imaging," Magnetic Resonance Imaging, vol. 4, no. 4, pp. 321-333, 1986.

[30] K. Katić, R. Li, and W. Zeiler, "Thermophysiological models and their applications: A review," Building and Environment, vol. 106, pp. 286-300, 2016. 
[31] M. Fu, W. Weng, W. Chen, and N. Luo, "Review on modeling heat transfer and thermoregulatory responses in human body," Journal of Thermal Biology, vol. 62, pp. 189-200, 2016.

[32] T. Nomura, I. Laakso, and A. Hirata, "FDTD computation of temperature elevation in the elderly for far-field RF exposures," Radiation Protection Dosimetry, vol. 158, no. 4, pp. 497-500, 2014.

[33] A. Hirata, I. Laakso, T. Oizumi, R. Hanatani, K. H. Chan, and J. Wiart, "The relationship between specific absorption rate and temperature elevation in anatomically based human body models for plane wave exposure from $30 \mathrm{MHz}$ to $6 \mathrm{GHz}$," Physics in Medicine and Biology, vol. 58, no. 4, pp. 903-921, 2013.

[34] D. A. Nelson, A. R. Curran, H. A. Nyberg, E. A. Marttila, P. A. Mason, and J. M. Ziriax, "High-resolution simulations of the thermophysiological effects of human exposure to $100 \mathrm{MHz}$ RF energy," Physics in Medicine and Biology, vol. 58, no. 6, pp. 19471968, 2013.

[35] I. Laakso and A. Hirata, "Dominant factors affecting temperature rise in simulations of human thermoregulation during RF exposure," Physics in Medicine and Biology, vol. 56, no. 23, pp. 7449-7471, 2011.

[36] A. Hirata, H. Sugiyama, and O. Fujiwara, "Estimation of core temperature elevation in humans and animals for whole-body averaged SAR," Progress in Electromagnetics Research, vol. 99, pp. 53-70, 2009.

[37] S. M. Moore, R. L. McIntosh, S. Iskra, A. Lajevardipour, and A. W. Wood, "Effect of adverse environmental conditions and protective clothing on temperature rise in a human body exposed to radiofrequency electromagnetic fields," Bioelectromagnetics, vol. 38, no. 5, pp. 356-363, 2017.

[38] A. Hirata, T. Asano, and O. Fujiwara, "FDTD analysis of human body-core temperature elevation due to RF far-field energy prescribed in the ICNIRP guidelines," Physics in Medicine and Biology, vol. 52, no. 16, article no. 020, pp. 5013-5023, 2007.

[39] B. J. Barber, D. J. Schaefer, C. J. Gordon, D. C. Zawieja, and J. Hecker, "Thermal effects of MR imaging: Worst-case studies on sheep," American Journal of Roentgenology, vol. 155, no. 5, pp. 1105-1110, 1990.

[40] J. A. D’Andrea, J. M. Ziriax, and E. R. Adair, "Radio frequency electromagnetic fields: mild hyperthermia and safety standards," Progress in Brain Research, vol. 162, pp. 107-135, 2007.

[41] L. Kheifets, M. Repacholi, and R. Saunders, "Thermal stress and radiation protection principles," International Journal of Hyperthermia, vol. 19, no. 3, pp. 215-224, 2003.

[42] R. D. Saunders, R. J. Croft, and E. Van Rongen, "Biological effects and health consequences of ELF and RF fields," Comprehensive Biomedical Physics, vol. 7, pp. 323-353, 2014.

[43] S. Morrison and K. Nakamura, "Central mechanisms for thermoregulation," Annual Review of Physiology, vol. 81, no. 1, pp. 285-308, 2019.

[44] G. C. Donaldson, W. R. Keatinge, and R. D. Saunders, "Cardiovascular responses to heat stress and their adverse consequences in healthy and vulnerable human populations," International Journal of Hyperthermia, vol. 19, no. 3, pp. 225-235, 2003.

[45] E. R. Adair, S. A. Kelleher, G. W. Mack, and T. S. Morocco, "Thermophysiological responses of human volunteers during controlled," Bioelectromagnetics, vol. 19, no. 4, pp. 232-245, 1998.

[46] https://now.aapmr.org/impaired-thermoregulation/, 2019.

[47] S. C. Adams, R. Schondorf, J. Benoit, and R. D. Kilgour, "Impact of cancer and chemotherapy on autonomic nervous system function and cardiovascular reactivity in young adults with cancer: A case-controlled feasibility study," BMC Cancer, vol. 15, no. 1, p. $414,2015$.

[48] Z. Sienkiewicz, E. Van Rongen, R. Croft, G. Ziegelberger, and B. Veyret, "A closer look at the thresholds of thermal damage: workshop report by an ICNIRP task group," Health Physics Journal, vol. 111, no. 3, pp. 300-306, 2016.

[49] K. Kräuchi, K. Konieczka, C. Roescheisen-Weich et al., "Diurnal and menstrual cycles in body temperature are regulated differently: A 28-day ambulatory study in healthy women with thermal discomfort of cold extremities and controls," Chronobiology International, vol. 31, no. 1, pp. 102-113, 2014.

[50] Z. Obermeyer, J. K. Samra, and S. Mullainathan, "Individual differences in normal body temperature: Longitudinal big data analysis of patient records," BMJ, vol. 359, Article ID j5468, 2017.

[51] H. Wang, B. Wang, K. P. Normoyle et al., "Brain temperature and its fundamental properties: A review for clinical neuroscientists," Frontiers in Neuroscience, vol. 8, pp. 1-17, 2014.

[52] E. A. Kiyatkin, "Brain temperature homeostasis: Physiological fluctuations and pathological shifts," Frontiers in Bioscience, vol. 15, no. 1, pp. 73-92, 2010.

[53] J. Nadobny, M. Szimtenings, D. Diehl, E. Stetter, G. Brinker, and P. Wust, "Evaluation of MR-induced hot spots for different temporal SAR modes using a time-dependent finite difference method with explicit temperature gradient treatment," IEEE Transactions on Biomedical Engineering, vol. 54, no. 10, pp. 18371850, 2007.

[54] Z. Wang, J. C. Lin, J. T. Vaughan, and C. M. Collins, "Consideration of physiological response in numerical models of temperature during MRI of the human head," Journal of Magnetic Resonance Imaging, vol. 28, no. 5, pp. 1303-1308, 2008.

[55] Z. Wang, J. C. Lin, W. Mao, W. Liu, M. B. Smith, and C. M. Collins, "SAR and temperature: Simulations and comparison to regulatory limits for MRI," Journal of Magnetic Resonance Imaging, vol. 26, no. 2, pp. 437-441, 2007.

[56] Z. Wang and C. M. Collins, "Effect of RF pulse sequence on temperature elevation for a given time-average SAR," Concepts in Magnetic Resonance, vol. 37, no. 4, pp. 215-219, 2010.

[57] P. Wust, H. Stahl, J. Löffel, M. Seebass, H. Riess, and R. Felix, "Clinical, physiological and anatomical determinants for radiofrequency hyperthermia," International Journal of Hyperthermia, vol. 11, no. 2, pp. 151-167, 1995.

[58] G. C. Van Rhoon, "Is CEM43 still a relevant thermal dose parameter for hyperthermia treatment monitoring?" International Journal of Hyperthermia, vol. 32, no. 1, pp. 50-62, 2016.

[59] F. Adibzadeh, R. F. Verhaart, G. M. Verduijn et al., "Association of acute adverse effects with high local SAR induced in the brain from prolonged RF head and neck hyperthermia," Physics in Medicine and Biology, vol. 60, no. 3, pp. 995-1006, 2015.

[60] J. Soukup, A. Zauner, E. M. R. Doppenberg et al., "The importance of brain temperature in patients after severe head injury: Relationship to intracranial pressure, cerebral perfusion pressure, cerebral blood flow, and outcome," Journal of Neurotrauma, vol. 19, no. 5, pp. 559-571, 2002.

[61] W. D. Dietrich and H. M. Bramlett, "Hyperthermia and central nervous system injury," Progress in Brain Research, vol. 162, pp. 201-217, 2007.

[62] E. A. Kiyatkin and H. S. Sharma, "Permeability of the bloodbrain barrier depends on brain temperature," Neuroscience, vol. 161, no. 3, pp. 926-939, 2009.

[63] L. Kessel, L. Johnson, H. Arvidsson, and M. Larsen, “The relationship between body and ambient temperature and corneal 
temperature," Investigative Ophthalmology \& Visual Science, vol. 51, no. 12, pp. 6593-6597, 2010.

[64] J. M. Dixon and L. Blackwood, "Thermal variations of the human eye," Transactions of the American Ophthalmological Society, vol. 89, pp. 183-193, 1991.

[65] J. A. Elder, "Ocular effects of radiofrequency energy," Bioelectromagnetics, vol. 24, no. 6, pp. S148-S161, 2003.

[66] N. Sharon, P. Z. Bar-Yoseph, E. Bormusov, and A. Dovrat, "Simulation of heat exposure and damage to the eye lens in a neighborhood bakery," Experimental Eye Research, vol. 87, no. 1, pp. 49-55, 2008.

[67] F. G. Shellock and J. V. Crues, "Corneal temperature changes induced by high-field-strength MR imaging with a head coil," Radiology, vol. 167, no. 3, pp. 809-811, 1988.

[68] T. W. Athey, "A model of the temperature rise in the head due to magnetic resonance imaging procedures," Magnetic Resonance in Medicine, vol. 9, no. 2, pp. 177-184, 1989.

[69] A. Massire, M. A. Cloos, M. Luong et al., "Thermal simulations in the human head for high field MRI using parallel transmission," Journal of Magnetic Resonance Imaging, vol. 35, no. 6, pp. 1312-1321, 2012.

[70] A. L. H. M. W. Van Lier, A. N. T. J. Kotte, B. W. Raaymakers, J. J. W. Lagendijk, and C. A. Van Den Berg, "Radiofrequency heating induced by $7 \mathrm{~T}$ head MRI: Thermal assessment using discrete vasculature or Pennes' bioheat equation," Journal of Magnetic Resonance Imaging, vol. 35, no. 4, pp. 795-803, 2012.

[71] T. M. Fiedler, M. E. Ladd, and A. K. Bitz, "SAR simulations \& safety," NeuroImage, vol. 168, pp. 33-58, 2018.

[72] S. Kodera, J. Gomez-Tames, and A. Hirata, “Temperature elevation in the human brain and skin with thermoregulation during exposure to RF energy," Biomedical Engineering Online, vol. 17, no. 1, 2018.

[73] F. Adibzadeh, G. C. Van Rhoon, G. M. Verduijn, N. C. NausPostema, and M. M. Paulides, "Absence of acute ocular damage in humans after prolonged exposure to intense RF EMF," Physics in Medicine and Biology, vol. 61, no. 2, pp. 488-503, 2015.

[74] S. S. Cheung, J. K. Lee, and J. Oksa, "Thermal stress, human performance, and physical employment standards," Applied Physiology, Nutrition, and Metabolism, vol. 41, pp. S148-S164, 2016.

[75] M. C. Ziskin and J. Morrissey, "Thermal thresholds for teratogenicity, reproduction, and development," International Journal of Hyperthermia, vol. 27, no. 4, pp. 374-387, 2011.

[76] J. W. Dreier, A.-M. N. Andersen, and G. Berg-Beckhoff, "Systematic review and meta-analyses: Fever in pregnancy and health impacts in the offspring," Pediatrics, vol. 133, no. 3, pp. e674-e688, 2014.

[77] L. Sass, S. K. Urhoj, J. Kjærgaard, J. W. Dreier, K. StrandbergLarsen, and A.-M. Nybo Andersen, "Fever in pregnancy and the risk of congenital malformations: A cohort study," $B M C$ Pregnancy and Childbirth, vol. 17, no. 1, pp. 413-422, 2017.

[78] J. S. Choi, H. K. Ahn, J. Y. Han et al., "A case series of 15 women inadvertently exposed to magnetic resonance imaging in the first trimester of pregnancy," Journal of Obstetrics \& Gynaecology, vol. 35, no. 8, pp. 871-872, 2015.

[79] J. G. Ray, M. J. Vermeulen, A. Bharatha, W. J. Montanera, and A. L. Park, "Association between MRI exposure during pregnancy and fetal and childhood outcomes," Journal of the American Medical Association, vol. 316, no. 9, pp. 952-961, 2016.

[80] J. W. Hand, Y. Li, and J. V. Hajnal, "Numerical study of RF exposure and the resulting temperature rise in the foetus during a magnetic resonance procedure," Physics in Medicine and Biology, vol. 55, no. 4, pp. 913-930, 2010.

[81] O. S. Eskandar, S. D. Eckford, and T. Watkinson, "Safety of diagnostic imaging in pregnancy. Part 2: magnetic resonance imaging, ultrasound scanning and Doppler assessment," The Obstetrician \& Gynaecologist, vol. 12, pp. 171-177, 2010.

[82] P. A. Gowland and J. De Wilde, "Temperature increase in the fetus due to radio frequency exposure during magnetic resonance scanning," Physics in Medicine and Biology, vol. 53, no. 21, pp. L15-L18, 2008.

[83] A. Hirata, Y. Ishii, T. Nomura, and I. Laakso, "Computation of temperature elevation in fetus due to radio-frequency exposure with a new thermal modeling," in Proceedings of the 2013 35th Annual International Conference of the IEEE Engineering in Medicine and Biology Society (EMBC), pp. 3753-3756, Osaka, Japan, July 2013.

[84] M. Murbach, E. Neufeld, T. Samaras et al., "Pregnant women models analyzed for RF exposure and temperature increase in 3T RF shimmed birdcages," Magnetic Resonance in Medicine, vol. 77, no. 5, pp. 2048-2056, 2017.

[85] A. Hirata, I. Laakso, Y. Ishii, T. Nomura, and K. H. Chan, "Computation of temperature elevation in a fetus exposed to ambient heat and radio frequency fields," Numerical Heat Transfer, Part A: Applications, vol. 65, no. 12, pp. 1176-1186, 2014.

[86] M. Murbach, E. Cabot, E. Neufeld et al., "Local SAR enhancements in anatomically correct children and adult models as a function of position within 1.5 T MR body coil," Progress in Biophysics and Molecular Biology, vol. 107, no. 3, pp. 428-433, 2011.

[87] T. Voigt, H. Homann, U. Katscher, and O. Doessel, "Patientindividual local SAR determination: In vivo measurements and numerical validation," Magnetic Resonance in Medicine, vol. 68, no. 4, pp. 1117-1126, 2012.

[88] M. Murbach, E. Neufeld, M. Capstick et al., "Thermal tissue damage model analyzed for different whole-body SAR and scan durations for standard MR body coils," Magnetic Resonance in Medicine, vol. 71, no. 1, pp. 421-431, 2014.

[89] M. Murbach, E. Neufeld, W. Kainz, K. P. Pruessmann, and N. Kuster, "Whole-body and local RF absorption in human models as a function of anatomy and position within 1.5T MR body coil," Magnetic Resonance in Medicine, vol. 71, no. 2, pp. 839845, 2014.

[90] M. Murbach, E. Neufeld, E. Cabot et al., "Virtual populationbased assessment of the impact of 3 Tesla radiofrequency shimming and thermoregulation on safety and B1+ uniformity," Magnetic Resonance in Medicine, vol. 76, no. 3, pp. 986-997, 2016.

[91] C. J. Gordon, Local and Global Thermoregulatory Response to MRI Electromagnetic Fields, U.S. Environmental Protection Agency, Washington, DC, USA, 1991, EPA/600/D-91/228 (NTIS PB91242941).

[92] G. Brix, M. Seebass, G. Hellwig, and J. Griebel, "Estimation of heat transfer and temperature rise in partial-body regions during MR procedures: An analytical approach with respect to safety considerations," Magnetic Resonance Imaging, vol. 20, no. 1, pp. 65-76, 2002.

[93] Z. Wang and J. C. Lin, "Partial-body SAR calculations in magnetic-resonance image (MRI) scanning systems," IEEE Antennas and Propagation Magazine, vol. 54, no. 2, pp. 230-237, 2012. 
[94] O. Szasz, G. Szigeti, and A. Szasz, "Connections between the specific absorption rate and the local temperature," Open Journal of Biophysics, vol. 06, no. 03, pp. 53-74, 2016.

[95] D. T. B. Yeo, Z. Wang, W. Loew, M. W. Vogel, and I. Hancu, "Local specific absorption rate in high-pass birdcage and transverse electromagnetic body coils for multiple human body models in clinical landmark positions at 3T," Journal of Magnetic Resonance Imaging, vol. 33, no. 5, pp. 1209-1217, 2011.

[96] D. Shrivastava, L. Utecht, J. Tian, J. Hughes, and J. Thomas Vaughan, "In vivo radiofrequency heating in swine in a 3T (123.2-MHz) birdcage whole body coil," Magnetic Resonance in Medicine, vol. 72, no. 4, pp. 1141-1150, 2014.

[97] H. Homann, P. Börnert, H. Eggers, K. Nehrke, O. Dössel, and I. Graesslin, "Toward individualized SAR models and in vivo validation," Magnetic Resonance in Medicine, vol. 66, no. 6, pp. 1767-1776, 2011.

[98] S. Wolf, D. Diehl, M. Gebhardt, J. Mallow, and O. Speck, "SAR simulations for high-field MRI: How much detail, effort, and accuracy is needed?" Magnetic Resonance in Medicine, vol. 69, no. 4, pp. 1157-1168, 2013.

[99] C. R. Roy and L. J. Martin, "A comparison of important international and national standards for limiting exposure to EMF including the scientific rationale," Health Physics Journal, vol. 92, no. 6, pp. 635-641, 2007.

[100] K. R. Foster, M. C. Ziskin, Q. Balzano, and G. Bit-Babik, "Modeling tissue heating from exposure to radiofrequency energy and relevance of tissue heating to exposure limits: heating factor," Health Physics Journal, vol. 115, no. 2, pp. 295307, 2018 .

[101] R. F. Verhaart, G. M. Verduijn, V. Fortunati et al., "Accurate 3D temperature dosimetry during hyperthermia therapy by combining invasive measurements and patient-specific simulations," International Journal of Hyperthermia, vol. 31, no. 6, pp. 686-692, 2015.

[102] F. F. Simonis, A. J. Raaijmakers, J. J. W. Lagendijk, and C. A. Van den Berg, "Validating subject-specific RF and thermal simulations in the calf muscle using MR-based temperature measurements," Magnetic Resonance in Medicine, vol. 77, no. 4, pp. 1691-1700, 2017.

[103] J. Nadobny, R. Klopfleisch, G. Brinker, and G. StoltenburgDidinger, "Experimental investigation and histopathological identification of acute thermal damage in skeletal porcine muscle in relation to whole-body SAR, maximum temperature, and $\mathrm{CEM} 43^{\circ} \mathrm{C}$ due to RF irradiation in an MR body coil of birdcage type at $123 \mathrm{MHz}$," International Journal of Hyperthermia, vol. 31, no. 4, pp. 409-420, 2015.

[104] P. S. Yarmolenko, E. J. Moon, C. Landon et al., “Thresholds for thermal damage to normal tissues: an update," International Journal of Hyperthermia, vol. 27, no. 4, pp. 320-343, 2011.

[105] J. A. Pearce, "Comparative analysis of mathematical models of cell death and thermal damage processes," International Journal of Hyperthermia, vol. 29, no. 4, pp. 262-280, 2013.

[106] J. Haveman, J. Van Der Zee, J. Wondergem, J. F. Hoogeveen, and M. C. C. M. Hulshof, "Effects of hyperthermia on the peripheral nervous system: A review," International Journal of Hyperthermia, vol. 20, no. 4, pp. 371-391, 2004.

[107] J. F. Hoogeveen, A. H. W. Van Der Kracht, J. Wondergem, and J. Haveman, "Effects of local hyperthermia on the sensitivity of rat sciatic nerve from diabetic rats," Neuroscience Research Communications, vol. 12, no. 2, pp. 63-70, 1993.
[108] E. Neufeld, M. Fuetterer, M. Murbach, and N. Kuster, "Rapid method for thermal dose-based safety supervision during MR scans," Bioelectromagnetics, vol. 36, no. 5, pp. 398-407, 2015.

[109] F. Adibzadeh, M. M. Paulides, and G. C. van Rhoon, "SAR thresholds for electromagnetic exposure using functional thermal dose limits," International Journal of Hyperthermia, vol. 34, no. 8, pp. 1248-1254, 2018. 


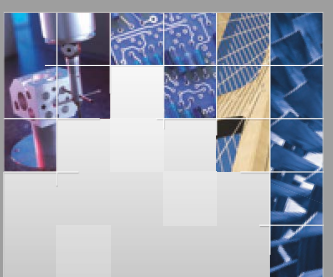

\section{Enfincering}
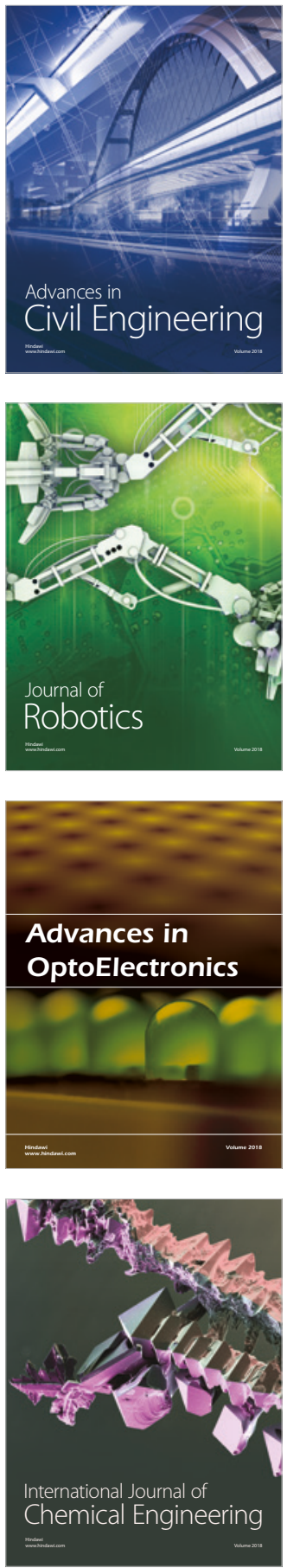

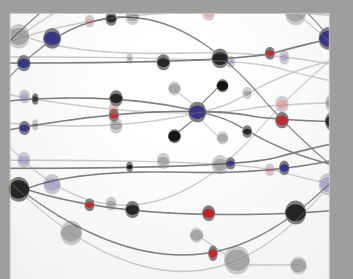

\section{Rotating \\ Machinery}

The Scientific World Journal

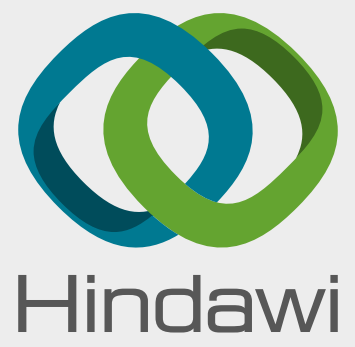

Submit your manuscripts at

www.hindawi.com
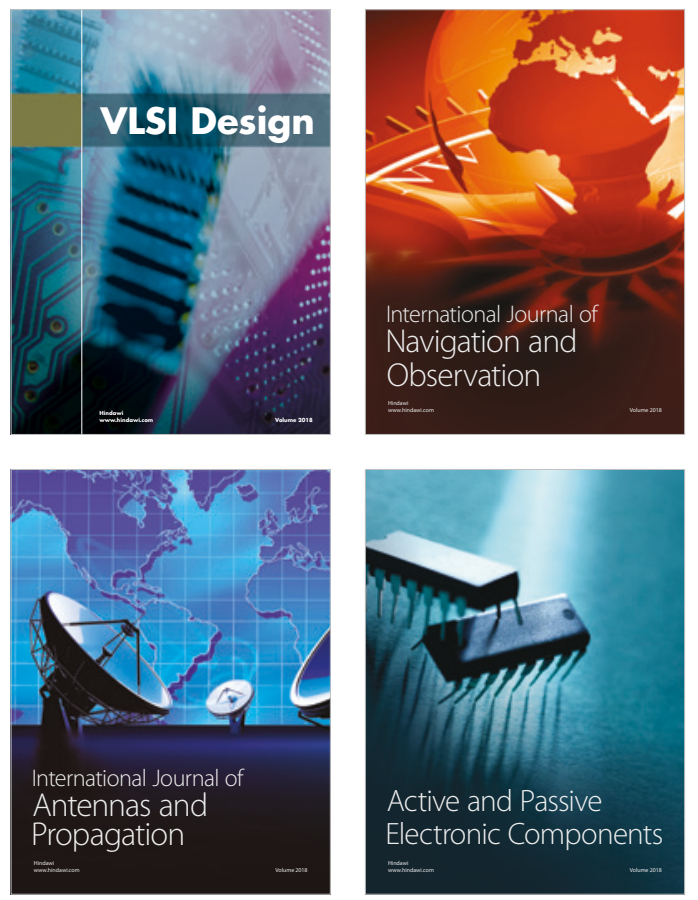
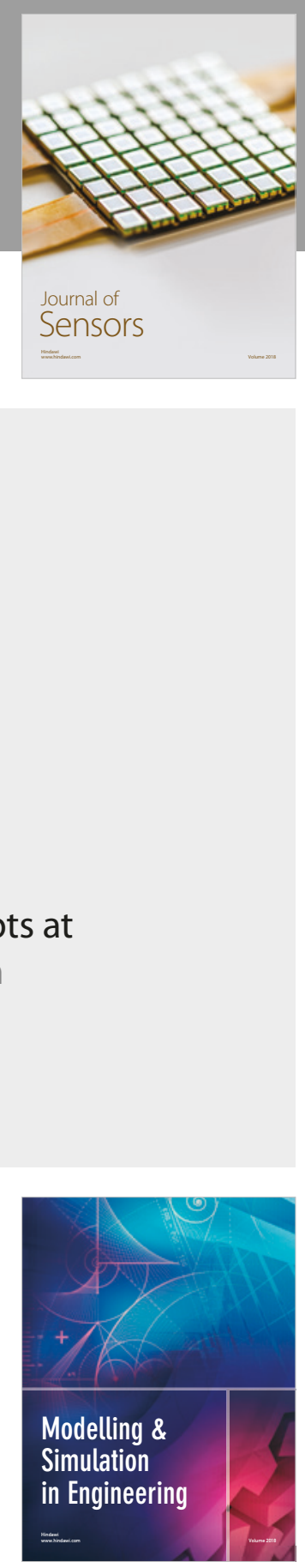

\section{Advances \\ Multimedia}
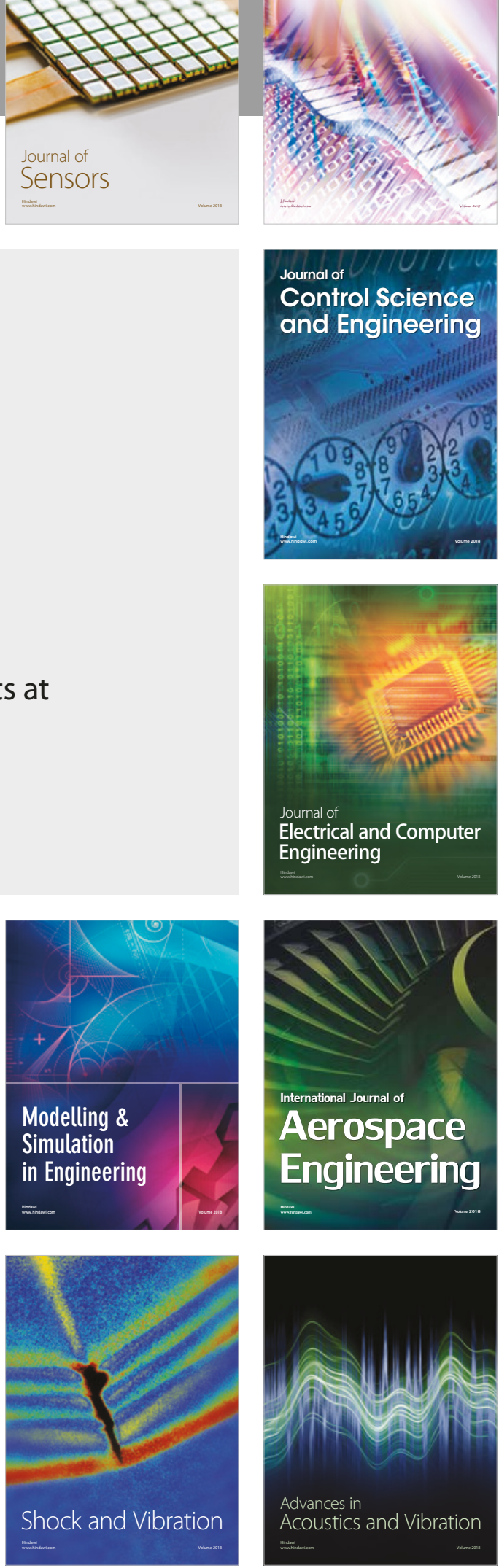